\title{
On the Interaction of Monetary and Fiscal Policy
}

Jagjit S. Chadha and Charles Nolan

January 2003

DAE Working Paper No. 0303

Not to be quoted without permission 


\begin{abstract}
In this chapter we review some fundamental issues that have been identified by macroeconomists in discussing the coordination of monetary and fiscal policy. As Sargent and Wallace (1981) graphically illustrated, the consolidated public sector present-value budget constraint means that monetary and fiscal policy are ultimately joint decisions. However, as we show in a quantitative general equilibrium model, even when fiscal solvency is not an issue, monetary and fiscal policy may still need to be coordinated.
\end{abstract}

JEL Classification: E21; E32; E52; E63.

Keywords: Optimal Simple Rules, Monetary and Fiscal Policy, Finite Lives. 


\title{
On the Interaction of Monetary and Fiscal Policy
}

\author{
Jagjit S. Chadha \\ University of Cambridge ${ }^{1}$ \\ and \\ Charles Nolan \\ University of Durham ${ }^{2} 3$
}

Forthcoming in Dynamic Macroeconomic Analysis: - Theory and Policy in General Equilibrium, Eds. Sumru Altug, Jagjit Chadha and Charles Nolan, Cambridge University Press, 2003.

\section{Introduction}

In this chapter we consider the interaction of monetary policy with aggregative fiscal policy. By 'aggregative' we mean that our focus is primarily on the effects of debts and deficits in the presence of lump-sum taxation. ${ }^{4}$ We shall, in particular, be concerned with the ways monetary and fiscal policies may need

\footnotetext{
${ }^{1}$ Clare College, Cambridge. Address: Department of Applied Economics, Austin Robinson Building, Sidgwick Avenue, University of Cambridge, Cambridge CB3 9DE, UK. Tel: +44 $1223 \quad 335242 . \quad$ E-mail: jagjit.chadha@econ.cam.ac.uk. http://www.econ.cam.ac.uk/dae/people/chadha/

${ }^{2}$ Department of Economics and Finance, 23/26 Old Elvet, Durham DH1 3HY. Tel +44 $191 \quad 374 \quad 7273 . \quad$ E-mail: Charles.Nolan@durham.ac.uk. http://www.dur.ac.uk/charles.nolan/index.html

${ }^{3}$ We should like to thank for useful comments on this research, Matthew Canzoneri, Sugata Gosh, Dale Henderson, Andrew Hughes Hallett, Campbell Leith, Bennett McCallum, Patrick Minford, Anna Schwartz, Frank Smets, Gabriel Talmain, Mike Wickens, Simon Wren-Lewis and conference participants at Birkbeck College, Cardiff University, Dundee University, Manchester University, York University and the European Central Bank. Anne Mason provided excellent assistance in the preparation of this document. All remaining errors are due to the authors.

${ }^{4}$ The chapter by Turnovsky discusses a number of central issues raised by the existence of distortionary taxes in the stochastic growth model. Chari and Kehoe (1999) is a recent comprehensive review of (Ramsey) optimal monetary and fiscal policies in the presence of distortionary taxation.
} 
to be coordinated to ensure 'good' macroeconomic outcomes. To that end, we shall be largely occupied with two issues: (a) the fundamental linkages between the government's budget constraint and the setting of interest rates and (b) on the stabilization issues thrown up by systematic fiscal and monetary policy over the economic cycle.

More specifically, we study how monetary policy may be influenced by doubts over the wider fiscal solvency of the public sector. In an important contribution Sargent and Wallace (1981) argued that the money stock and taxes were substitutes in the backing of government debt. This discussion brings to the fore the fact that monetary and fiscal policies are linked via a budget constraint. However, many countries have recently delegated control of monetary policy to an independent monetary authority, partly in response to the kind of concerns raised by Sargent and Wallace. There now seems to be some concern that monetary and fiscal policy may actually not be well coordinated under such an institutional structure. The issue seems less to do with solvency, and more to do with aggregate demand management over the economic cycle: if monetary policy is too 'rigid', then fiscal policy may need to compensate by being more 'flexible'. So the second issue we discuss is how monetary and fiscal policies might be set jointly in order to smooth the economic cycle.

In the next section we set out the contents of the chapter in some more detail.

\subsection{Key Themes}

Following Sargent and Wallace $(1975,1981)$ macroeconomists generally argued that there were two key requirements for monetary policy to retain control over nominal magnitudes. First, monetary policy ought to be characterized by control over the money stock as opposed to an interest rate peg. However, since fiscal policy may hamper the effective control of the money supply by requiring excessive 
seigniorage revenue - the tax revenue generated from money creation - this is not, in general, a sufficient condition. As we show in sections 2 and 3, the consolidated public sector budget constraint is the key equation linking the joint feasible sequences of monetary and fiscal variables through time. A government which runs a persistent deficit may require monetary policy to plug the hole in the public sector finances. Consequently, for monetary policy to retain control over nominal magnitudes in the economy, fiscal policy must take seigniorage as given and provide a temporal, (state-dependent) sequence of net deficits in order that debt satisfies a no-Ponzi condition.

Through the 1980s the US started to run large and what were expected to be long-lasting fiscal deficits, and the concerns of Sargent and Wallace (1981) moved centre stage. However, McCallum (1984) argued that it was not at all apparent that persistent deficits would compromise the ability of monetary policy to control the price-level. He showed that a key issue was how one defined the deficit. If one included interest payments in the definition of the deficit, as is common, then permanent deficits were perfectly feasible without recourse to seigniorage revenue.

In a related analysis, Aiyagari and Gertler (1985) demonstrated that if bonds were not fully backed by taxes then the price-level would show a proportionate relationship to the value of outstanding bonds.

Although focussing on different fiscal rules, these two contributions are essentially refinements of the Sargent and Wallace (op. cit.) intuition. However, one may question whether the issues considered in these analyses are of firstorder importance. In many models, the real side of the economy, consumption, real interest rates and so on, is largely immune to fiscal policy developments by virtue of Ricardian Equivalence. ${ }^{5}$ However, a more recent approach to analyzing

\footnotetext{
${ }^{5} \mathrm{We}$ are being a little cavalier here. While the statement is basically right in representative agent models with lump-sum taxes (given a path of government expenditure), real variables will in general respond to shocks to government expenditure. See for example, Baxter and King
} 
the interaction of monetary and fiscal policy, the fiscal theory of the price-level, argues that the requirements for a rational expectations equilibrium to obtain in standard models of a monetary economy, are stricter than is often acknowledged. And in so arguing it demonstrates that prices and output may indeed be influenced strongly by fiscal policy, even without distortionary taxes, liquidity constraints, and so on.

The fiscal theory of the price-level (FTPL), developed by, among others, Leeper (1991), Sims (1994, 1999), Woodford (1995, 1997, 1998a) and Cochrane (2001), argues that the public-sector budget constraint imposes few restrictions on the joint choices for monetary and fiscal variables. In the FTPL the government's present value budget constraint determines the equilibrium price-level. That is, if the expected discounted sequence of net surpluses or deficits is not identically equal to outstanding debt, then the price-level must change in order to bring these magnitudes into equality. For holders of nominal government debt such changes in the price-level alter the value of real consumption units to which the nominal debt lays claim. The resulting wealth effect changes equilibrium consumption, output, interest rates and the price level. However, this approach has proved controversial encouraging a sometimes vigorous debate amongst its supporters and detractors. ${ }^{6}$

One advantage that the FTPL may have is that it resolves the problem of pricelevel indeterminacy under an interest rate rule. This problem was highlighted by the earlier contribution of Sargent and Wallace (1975). If the present-value budget constraint ties down the price-level, we might consider the monetary authority to be setting the interest rate in a way that may be consistent with how central

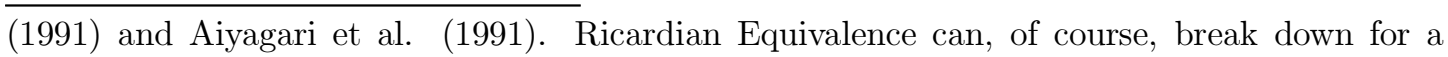
number of other reasons, such as incomplete markets (e.g., liquidity constraints), disortionary taxation, non-rational expectations, and so on.

${ }^{6}$ See for example, Buiter, $(1998,1999)$ who is highly critical of the FTPL and Cochrane, (1998, 2001a, b), who is strongly supportive. 
banks act in practice. ${ }^{7}$ However, this comes at a price as monetary policy no longer controls inflation (although it may still influence expected inflation), and macroeconomic stability may have more to with fiscal policy than monetary policy. That said, it may it may be very hard in practice to disentangle the effects of monetary and fiscal rules. However the overriding criticism of the FTPL appears to be that it permits the fiscal sector to operate without respecting a budget constraint, even though the PVBC will be satisfied in equilibrium.

It is increasingly common for theoretical macroeconomics to assume that the short-term nominal interest rate (as opposed to the money supply) is the instrument of monetary policy. In sections 4-6, therefore, as a prelude to our discussion of the joint conduct of monetary and fiscal policy over the business cycle, we investigate further the implications of the PVBC for monetary policy. In section 7 to 10 we develop a highly stylized dynamic stochastic general equilibrium model in which both monetary and fiscal policy have leverage over aggregate demand. We necessarily incorporate the consolidated public sector budget constraint, but assume that fiscal policy is set over time to ensure that the PVBC is met. We then investigate the jointly optimal policies for monetary policy and fiscal policy given a key objective of stabilizing aggregate demand and find that our interest rate rule ends up being parameterized remarkably closely to the original recommendations of Taylor (1993). Our rule for fiscal policy also ends up being parameterized such that the implied deficit:GDP ratio tracks reasonably closely recently observed values in both the US and UK. We also analyze what might happen if one or the other policy rule 'misbehaves'.

We offer some conclusions and suggestions for further research in section 11.

\footnotetext{
${ }^{7}$ Whether or not the FTPL does indeed resolve this indeterminacy issue is a matter, like much else related to the FTPL, of some controversy; see McCallum (2001).
} 


\section{Sargent and Wallace (1981) and What Came Next}

For expositional ease, and for consistency with what we present in Sections 710, we shall present the key results in this section using a representative agent framework. We do not model the factor markets and we assume that there is no population growth. This set up means we cannot analyze all the issues raised in some of the original contributions that we draw on. However, we do find it easier to relate the analyses to one another and more recent contributions. Finally, until section 7 we shall in general only consider perfect foresight economies under priceflexibility, although there are some important exceptions in between. We shall make clear when we drop these assumptions.

Consider a closed economy inhabited by a large number of identical agents. Each agent's utility is defined over the real consumption stream, $\left\{C_{t}\right\}_{t=0}^{\infty}$, and the stream of real money balances, $\left\{\frac{M_{t}}{P_{t}}\right\}_{t=0}^{\infty}$. We motivate the incorporation of base money in the utility function, in the manner of Sidrauski (1965) and Brock (1975), by appealing to the notion that money eases transactions costs. The discounted present value of utility is therefore given by,

$$
V_{t}=\sum_{t=0}^{\infty} \beta^{t} U\left(C_{t}, \frac{M_{t}}{P_{t}}\right),
$$

where $U(\cdot)$ denotes a utility function increasing in both arguments, strictly concave and obeying familiar Inada-type conditions (see Obstfeld and Rogoff, 1983). In addition we shall also find it convenient to assume that $U(\cdot)$ is separable in its arguments. This keeps the analysis somewhat simpler than it otherwise would be in one or two places. Specifically, we shall assume that $U(\cdot)=u\left(C_{t}\right)+v\left(M_{t} / P_{t}\right) \cdot \beta \in(0,1)$ is the discount factor which equals $(1+\delta)^{-1}$, where $\delta>0$ is the subjective rate of time preference. The representative agent maximizes (2.1) each period subject to the following sequence of flow budget 
constraints,

$$
P_{t} C_{t}+M_{t}+\frac{B_{t}}{1+i_{t}} \leq M_{t-1}+B_{t-1}+P_{t} Y_{t}-P_{t} T_{t} \quad \forall t \geq 0
$$

$M_{-1}$ and $B_{-1}$ given. $P_{t}$ is the price-level in period $t, M_{t}$ and $B_{t}$ are, respectively, nominal money balances and one period (discount) nominal debt held at the end of period $t . Y_{t}$ is the endowment in period $t$ and $T_{t}$ denotes lump sum taxes. The first-order conditions for an interior optimum include (2.2) with equality at each date $t$, a relationship equating the marginal utility of money holdings to the marginal cost,

$$
\frac{v^{\prime}\left(M_{t} / P_{t}\right)}{u^{\prime}\left(C_{t}\right)}=\frac{i_{t}}{1+i_{t}} \quad \forall t \geq 0
$$

and a relationship characterizing optimal consumption and savings through time:

$$
\beta \frac{u^{\prime}\left(C_{t+1}\right)}{u^{\prime}\left(C_{t}\right)} \frac{P_{t}}{P_{t+1}}=\frac{1}{1+i_{t}} \quad \forall t \geq 0 .
$$

It follows that the price-level will be governed by the following nonlinear difference equation,

$$
P_{t+1}=i_{t} \beta P_{t}\left[\frac{u^{\prime}\left(C_{t+1}\right)}{v^{\prime}\left(M_{t} / P_{t}\right)}\right]
$$

It is well known that this equation will admit multiple equilibria, some of which may be ruled out via appeal to familiar conditions on the budget set, as in Obstfeld and Rogoff (1983), but others which cannot. These conditions essentially constrain the optimal consumption programme such that borrowing is limited by lifetime resources. This condition is implied by the intertemporal sequence of equations in (2.2), along with the requirement that,

$$
\lim _{T \rightarrow \infty}\left\{\prod_{j=0}^{T-1}\left(1+i_{t+j}\right)\right\}^{-1} W_{t+T} \rightarrow 0 .
$$


Here we denote $W_{t} \equiv M_{t-1}+B_{t-1}$. This is often labelled the no-Ponzi finance condition and permits us to rule out equilibria in which, for a given money stock, the price level tends to zero. (2.6) is therefore also considered a requirement for an optimum.

The question now is: In what ways does the fiscal-monetary framework affect the workings of this simple economy? As a first pass at this issue, we shall consider the economy outlined above in steady state. Specifically, consider a steady state in which $M_{t} / M_{t-1}=P_{t+1} / P_{t}=\mu=\pi_{t+1}+1$. Since, as we just indicated, the evolution of prices need not necessarily be consistent with this steady state we ought to establish that such a steady state is worthy of our interest. In practice many economists have been persuaded of the importance of this steady state since otherwise self-fulfilling hyperinflations or hyperdeflations result. ${ }^{8}$ When we analyze below the fiscal theory of the price-level we shall return to this equilibrium selection issue. Then, with lower case letters generally denoting real steady-state values, the representative consumer's optimality conditions become,

$$
\begin{aligned}
\delta & =r, \\
\frac{v^{\prime}(m)}{u^{\prime}(c)} & =\frac{r}{1+r},
\end{aligned}
$$

and

$$
c-(\mu-1) m-b\left(\frac{r}{1+r}\right)=y-t .
$$

Now note that the government per-period budget constraint is given by

$$
\frac{B_{t}}{\left(1+i_{t}\right)}=B_{t-1}+P_{t}\left(G_{t}-T_{t}\right)-\left(M_{t}-M_{t-1}\right) \quad \forall t \geq 0
$$

\footnotetext{
${ }^{8} \mathrm{Or}$, to put the matter more succinctly, many economists have been persuaded by Milton Friedman that inflation is a monetary phenomenon.
} 
The variables in (2.10) are as defined previously, with $G_{t}$ now denoting real government expenditure. This expression is analogous to the agent's flow constraint and together (2.2) and (2.10) imply the economy-wide resource constraint,

$$
C_{t}+G_{t}=Y_{t} \quad \forall t \geq 0
$$

And since the representative agent's optimal consumption programme is constrained by lifetime resources it follows that the sequence of equations (2.10) will be consistent with the representative agent's consumption programme if and only if a requirement analogous to (2.6) is imposed on the government's net issue of debt,

$$
\lim _{T \rightarrow \infty}\left\{\prod_{j=0}^{T-1}\left(1+i_{t+j}\right)\right\}^{-1} W_{t+T} \rightarrow 0 .
$$

In turn, then, it follows that (2.10) and (2.12) together imply that,

$$
B_{t-1}+M_{t-1}=\sum_{j=0}^{\infty}\left\{\prod_{s=j}^{j-1}\left(\frac{1}{1+i_{t+s}}\right)\left[P_{t+j}\left(T_{t+j}-G_{t+j}+\frac{i_{t+j}}{1+i_{t+j}} M_{t+j}\right]\right\} .\right.
$$

The traditional interpretation of (2.13) is that it determines the necessary discounted value of taxation (including seigniorage) given the outstanding real value of government liabilities, $\left(B_{t-1}+M_{t-1}\right) / P_{t}$. This interpretation is, therefore, entirely analogous to the interpretation of the representative agent's present-value budget constraint, and implies that (2.13) is a constraint that holds identically for all feasible price-level sequences. In turn, such a restriction implies that the fiscalmonetary programme will operate to ensure that whatever the real outstanding level of government liabilities, sufficient net taxation will be forthcoming to ensure that (2.13) holds identically. A key implication of this perspective is that monetary and fiscal policy, in setting the left hand side of (2.13), are potential substitutes 
in the backing of outstanding liabilities. Most obviously, a rise in outstanding interest bearing liabilities that does not elicit an equal present valued increase in tax revenue requires necessarily an increase in seigniorage. Equally, there exists an additional requirements upon the joint design of monetary and fiscal policy such that monetary policy is capable of determining the evolution of nominal magnitudes in the economy.

There are a number of useful ways to view the restrictions typically associated with the government's financing constraint. First let us consider the budget constraint in the constant inflation steady state set out above. In addition, consider what happens in that steady state when it is also characterized by a constant level of interest bearing debt. We emphasize that there is nothing special about such a steady state, particularly with respect to our assumption of steady state debt. In particular, as we shall see, debt need not in fact be constant in steady state, even with a constant inflation rate. However, for now, it will help fix ideas to consider such a situation. In that case the government's budget constraint implies

$$
b=\left[\frac{1+r}{r}\right](G-T)+\left[\frac{1+r}{r}\right](\mu-1) m .
$$

Following Calvo (1985) assume further a situation in which in this steady state the government raises sufficient funds via taxation to cover government expenditure. In that case, we find that

$$
\pi=\frac{b}{m}\left(\frac{r}{1+r}\right)
$$

Equation (2.7) pins down the steady state interest rate (making it equal to the subjective rate of discount), while (2.8) determines the steady state demand for money, given the steady state level of consumption and the discount rate. Hence equation (2.15) in turn implies a positive relationship between inflation and bonds. This is the essence of the Sargent and Wallace (1981) contention that 
control of monetary policy, and hence control of inflation, may be compromised when the fiscal authority is 'dominant', which may imply a stronger commitment technology. Equation (2.15) indicates that a rise in outstanding bonds, absent any change in the steady state net primary surplus, implies that steady state inflation must be higher. The mechanism is clear: the budget constraint needs to be met and if taxes do not adjust then it falls to seigniorage to meet the shortfall. In each of the subsequent analyses, except for the fiscal theory of the price-level, it is this simple logic that requires monetary and fiscal policy to be linked.

Let us now consider another implication of the joint sequence of equations (2.10) and (2.12). First, note that $P_{t+1} / P_{t} \equiv\left(1+\pi_{t+1}\right)$, and also that, for any variable $X_{t}$, deflated by the previous period price-level it will be convenient to write $X_{t+1} / P_{t}=\left(X_{t+1} / P_{t+1}\right)\left(1+\pi_{t+1}\right)$. In real terms, the flow period $t$ constraint may be written as

$$
\frac{b_{t}}{1+r_{t}}=b_{t-1}+G_{t}-T_{t}-\left[m_{t}\left(1+\pi_{t+1}\right)-m_{t-1}\right]
$$

where $m \equiv M / P$. Let us assume that the real interest rate is constant. Iterating forward on this equation in the usual way, we find that

$b_{t-1}+m_{t-1}=\frac{b_{t+T}+m_{t+T}}{(1+r)^{T+1}}+\sum_{j=0}^{T}\left[\frac{\left[\left(r+(1+r) \pi_{t+j+1}\right) /(1+r)\right] m_{t+j}}{(1+r)^{j}}\right]+\sum_{j=0}^{T}\left[\frac{\tau_{t+j}-g_{t+j}}{(1+r)^{j}}\right]$.

However, as we noted above, the other side of the representative agent's transversality condition is an analogous condition on fiscal-monetary sequences, such that as $T \rightarrow \infty$ we have that

$b_{t-1}+m_{t-1}=\sum_{j=0}^{\infty}\left(\frac{1}{1+r}\right)^{j}\left[\frac{r+(1+r) \pi_{t+j+1}}{1+r}\right] m_{t+j}+\sum_{j=0}^{\infty}\left(\frac{1}{1+r}\right)^{j}\left[\tau_{t+j}-g_{t+j}\right]$,

since in that case

$$
\lim _{T \rightarrow \infty} \frac{b_{t+T}+m_{t+T}}{(1+r)^{T+1}}=0
$$


Some of the issues raised by Sargent and Wallace may now be observed from the standpoint of the present-value budget constraint (PVBC). Let $K$ denote the present value of outstanding liabilities and net of interest deficits. That is,

$$
\sum_{j=0}^{\infty}\left(\frac{1}{1+r}\right)^{j}\left[\frac{r+(1+r) \pi_{t+j+1}}{1+r}\right] m_{t+j}=K .
$$

Crucially, we assume that the arm of government responsible for seigniorage revenue takes the right hand side of $(2.20)$ as given. Consider, now, the consequences of a temporary change in seigniorage revenue raised in period $t$, but compensated for with a one-off rise in period $t+T$. It follows that,

$$
\frac{d m_{t+T}}{d m_{t}}=-\frac{\left[r+(1+r) \pi_{t+1}\right](1+r)^{T}}{\left[r+(1+r) \pi_{t+T+1}\right]} .
$$

In other words, any change in the real money stock requires a larger change (in the opposite direction) in $T$-periods time, with a factor of proportionality that is rising through time. ${ }^{9}$ It appears that postponing the raising of seigniorage runs the risk of a proportionately larger inflation in the future than may be required 'today'. ${ }^{10}$

The overriding concern raised by Sargent and Wallace boils down the institutional framework surrounding monetary and fiscal policy. For example, might policymakers find it optimal and feasible to extricate themselves from a highly indebted position via an inflation of the price-level? Sargent (1987, p176) attributes to Wallace the view that monetary and fiscal authorities may be engaged in a 'game of chicken' with either side trying to force the other's hand to meet the obligations of the PVBC. If such a game were to take place then there

\footnotetext{
${ }^{9}$ Our example of the Sargent and Wallace concerns is clearly somewhat simplified. Sargent (1987) Proposition 5.5, p 173, extends the above example of a one-off shift in the money stock to the case of changes in the temporal sequence of the money supply. The intuition is, however, the same.

${ }^{10}$ Actually, the authorities may not be able to put the fiscal day of reckoning off. If the pricelevel is a forward-looking variable rational agents may anticipate the higher future price-level.
} 
must be a presumption that the fiscal authority has an in-built advantage in the real world. Consequently, in the presence of some limit to the demand for bonds, a sequence of deficits may simply end up forcing the monetary authority to step in and provide the requisite seigniorage revenue. ${ }^{11}$

\subsection{How constrained is monetary policy?}

Through the second half of the 1970s fiscal deficits became more persistent in the US and ballooned in the 1980s and first half of the 1990s. The concerns raised by Sargent and Wallace (1981) seemed very relevant. Indeed these persistent deficits caused some economists even to question whether or not the public sector was meeting the present-value budget constraint. ${ }^{12}$ However, arguably a more fruitful line of enquiry was to enquire just how tolerant monetary policy could be of persistent deficits without surrendering de facto control of inflation. How extensive would the effects be on inflation of a run of deficits, or even a permanent sequence of deficits? This was the subject of McCallum (1984). McCallum enquired whether or not monetary policy might retain control of the price-level in the face of just such a sequence of permanent deficits. Following McCallum let us define a 'monetarist equilibrium' in which inflation is zero. Let us set $\mu=1$. In that case we have, $\pi=0$, since $\pi=\mu-1$. Alternatively, $m_{t}\left(1+\pi_{t+1}\right)-m_{t-1}=0$, $\forall t$. We shall investigate the extent to which fiscal policy might exclude such a situation from being a feasible outcome. First of all note that this implies that

\footnotetext{
${ }^{11}$ Would fiscal authorities find such shifts in the price-level optimal? The Ramsey-inspired approach to policy trade-offs identifies some important factors. On the one hand a bout of inflation acts like a lump sum tax. If the only other sources of revenue are via distortionary taxation, then inflation may have an obvious attraction. On the other hand, if there are rigidities in private sector price setting unanticipated inflation is far from costless. Results presented in Schmitt-Grohe and Uribe (2002) suggest that optimal policy will ensure substantial stability in the aggregate price level.

${ }^{12}$ The key contribution to this literature is Hamilton and Flavin (1986). However, see Bohn (1995) for a critical assessment of the literature following Hamilton and Flavin (op cit).
} 
(2.16) may be rewritten as

$$
\frac{b_{t}}{1+r_{t}}=b_{t-1}+\left(g_{t}-\tau_{t}\right)
$$

We adopt the following notation: $\left(g_{t}-\tau_{t}\right)=d, \forall t$. It follows then, assuming a constant interest rate, that

$$
b_{t+T}=(1+r)^{T+1} b_{t-1}+(1+r) d \sum_{j=0}^{T}(1+r)^{j} .
$$

In turn this implies that

$$
\frac{b_{t+T}}{(1+r)^{T+1}}=b_{t-1}+d \sum_{j=0}^{T}\left(\frac{1}{1+r}\right)^{j} .
$$

The final term on the right hand side may be written as $d\left[\frac{1-\left(\frac{1}{1+r}\right)^{T}}{1-\left(\frac{1}{1+r}\right)}\right]$. This expression does not converge to zero through time, since as $T \rightarrow \infty$ we see that

$$
\frac{b_{t+T}}{(1+r)^{T+1}}=b_{t-1}+\frac{1+r}{r} d .
$$

However, since the PVBC must hold, a zero inflation equilibrium is not feasible under rule (2.22); permanent deficits in this sense are indeed inconsistent with the monetarist equilibrium. In contrast to (2.22), now consider a process for debt of the following sort:

$$
b_{t}=b_{t-1}+d_{t}^{*}(1+r)
$$

where $d^{*}$ denotes the deficit inclusive of interest payments, $d_{t}^{*} \equiv\left(g_{t}+\frac{r b_{t-1}}{1+r}-\tau_{t}\right)$. Furthermore, let us assume that the fiscal authority attempts to fix the deficit to its value at time $t$ for all $t+j$, for $j \geq 0$. This rule implies that at time $T$ the outstanding level of debt will be given by,

$$
\frac{b_{t+T}}{(1+r)^{T+1}}=\frac{b_{t-1}}{(1+r)^{T+1}}+\frac{(T+1) d^{*}}{(1+r)^{T}} .
$$


We note that the first term on the right hand side of this expression clearly converges to zero for $T \rightarrow \infty$. The second term on the right hand side follows a somewhat circuitous route, rising initially before falling. Intuitively, whilst the numerator is rising linearly through time, the denominator is rising exponentially through time. As $T \rightarrow \infty$, it follows then that $\frac{b_{t+T}}{(1+r)^{T+1}} \rightarrow 0$, as required. The intuition is that by including interest payments in the definition of the deficit, the government repays a sufficient amount of debt each period and hence meets the PVBC. ${ }^{13}$ In this sense permanent deficits are a feasible policy for the fiscal authority in the presence of a zero inflation monetary policy.

However, even on this definition of the deficit, there are some unappealing implications for the evolution of taxes. In particular, the sequence of taxes required to support such a permanent deficit is itself unbounded. It can be shown that the sequence of taxes necessary for $d_{t}^{*}=d^{*}$ for all $t$ is given by

$$
\left\{\tau_{t+j}\right\}_{j=0}^{\infty}=\left\{g_{t+j}+\frac{r b_{t-1}}{1+r}+(1-j r) d\right\}_{j=0}^{\infty},
$$

which in turn can be used in (2.27) to yield a formula for the deficit inclusive of interest:

$$
\frac{r}{1+r}\left[\sum_{j=0}^{\infty}\left\{\left(\sum_{s=0}^{j-1} b_{t+s}-b_{t+s-1}\right)+(1-j r) d\right\}\right],
$$

where the first term within the summation is a sequence of terms in the growth of outstanding debt. ${ }^{14}$ We see, therefore, that taxes are rising linearly through time. Although the level of debt is rising through time the constant valued deficit implies a growth in interest payments that is declining through time. Consequently, the growth in taxes is also falling through time but necessarily at a rate initially less

\footnotetext{
${ }^{13}$ The ever-rising interest payments on the outstanding debt enable agents to pay the everrising taxes. See below.

${ }^{14}$ We adopt the convention, $\sum_{s} \equiv 0$, for $j=0$.
} 
than that of the debt service. The primary deficit is therefore constrained in this set up to fall without bound such that taxes raised are sufficient to meet the ever rising interest bill on the rising stock of debt. ${ }^{15}$

Aiyagari and Gertler (1985) widen the notion of 'monetarism' relative to McCallum's. In addition to the notion that the price-level is determined by the money supply, they also investigate wether or not money is unique in its effects on other economic variables, whether it matters if fiscal policy or monetary policy causes variation in the money stock, and whether a strict Fisher relation obtains between nominal interest rates and expected money growth. It is not possible to review all the results in this contribution. However, a notable result, that the price-level may be closely tied to the level of government debt has been of more recent interest since it has become something of a forerunner of the fiscal theory of the price-level. Consider a rule for raising tax revenues of the following sort.

$$
T_{t}=\left[G_{t}+\psi B_{t-1}-\frac{\psi B_{t}}{1+i_{t}}\right] .
$$

For $0<\psi<1$, this says that outstanding government bonds are not completely backed by taxes. Using this in (2.10) and simplifying we get that

$$
\frac{(1-\psi)}{1+i_{t}} B_{t}=(1-\psi) B_{t-1}-M_{t}+M_{t-1}
$$

As before we may write this in real terms, such that

$$
\frac{1+\pi_{t+1}}{1+i_{t}}\left[\left(1+i_{t}\right) \frac{M_{t}}{P_{t+1}}+(1-\psi) \frac{B_{t}}{P_{t+1}}\right]=(1-\psi) \frac{B_{t-1}}{P_{t}}+\frac{M_{t-1}}{P_{t}} .
$$

Using (2.2) under the assumption of $\log$ separability (that is $U=\log C+$

\footnotetext{
15 In addition McCallum also demonstrates that the deficit growth need not, even in this no-growth economy, literally go to zero to ensure fiscal solvency, although there is a bound on the possible growth rate which is determined by the steady state rate of interest in the economy. We postpone until section 4 discussion of the interaction between fiscal solvency and the interest rate.
} 
$\chi \log (M / P), \chi>0)$ we get that

$$
\frac{1}{1+r_{t}}\left[\frac{M_{t}}{P_{t+1}}+(1-\psi) \frac{B_{t}}{P_{t+1}}\right]+\chi C_{t}=(1-\psi) \frac{B_{t-1}}{P_{t}}+\frac{M_{t-1}}{P_{t}},
$$

where we have used that,

$$
\frac{1+\pi_{t+1}}{1+i_{t}} i_{t} \frac{M_{t}}{P_{t+1}}=\chi\left(\frac{1+\pi_{t+1}}{1+i_{t}}\right)\left(1+i_{t}\right) C_{t}=\chi \frac{1+i_{t}}{1+r_{t}} C_{t} .
$$

It is straightforward to rearrange equation (2.32) and recover an expression governing the evolution of the equilibrium price-level of the form (2.5), (or 2.37 below, using our assumed functional forms). However, following Walsh (1998), it may be more useful to solve for the steady-state price-level in this set-up. In steady state we have that $C=Y, i=r=\delta$. Therefore from (2.32) we see that,

$$
P=\frac{\delta}{1+\delta} \frac{M+(1-\psi) B}{\chi Y} .
$$

In the event that taxes fully back debt issue, then a steady-state equilibrium of our model exists in which the price-level will be directly proportional to the money supply in the way the simple quantity theory might suggest. However, to the extent that taxes do not fully support debt issue then we see that the price-level will bear a proportionate relationship to the stock of outstanding debt. Indeed there exists a continuum of solutions for the price-level indexed on $\psi$. The intuition is essentially that of Sargent and Wallace, if 'real' taxes are not backing public sector liabilities then seigniorage will be required.

\subsection{The Fiscal Theory of the Price-Level}

In all of the above contributions, the tension between monetary and fiscal policy was as a result of the PVBC. This needed to be met identically for all feasible values of the model's variables (and in all feasible states, in a stochastic environment). But need monetary policy so constrain fiscal policy? Indeed, 
need fiscal policy so constrain monetary policy? If we relax the assumption that the PVBC is an identity, how does the equilibrium of our simple model change? A recent literature due to Leeper (1991), Sims (1994, 1999), Woodford (1995, 1997, 1998a) and Cochrane (2001a), relaxes the requirement that the PVBC is an identity, although it is retained as an equilibrium relationship (as it must in fact be for the representative agents budget set to be well defined, in the usual sense). A defining characteristic of this fiscal theory of the price-level (FTPL) is a presumption that in the real world, monetary and fiscal authorities do not typically coordinate their 'actions' - specifically their temporal (contingency) sequences for the money stock (or interest rates), tax rates, and government expenditure. In the absence of such coordination does this simply lead to, in Buiter's (2000) terminology, default or supersolvency? The fiscalist writers argue in the negative. They point out that with nominal value of debt predetermined, and the future (expected) discounted stream of net deficits in some sense exogenous, the pricelevel today (and in the future, see Cochrane, 2001) can 'jump' to ensure that in equilibrium, the PVBC does nevertheless hold. Specifically, let us continue to use the simple framework outlined above, which assumes two types of government liabilities, one period discount nominal debt, and base money that returns no interest to its holder. As before, we may write the PVBC facing the public sector (loosely, the consolidated government and central bank balance sheet) as follows:

$$
\frac{B_{t-1}+M_{t-1}}{P_{t}}=\sum_{j=0}^{\infty}\left(\frac{1}{1+r}\right)^{j}\left[\frac{r+(1+r) \pi_{t+j+1}}{1+r}\right] m_{t+j}+\sum_{j=0}^{\infty}\left(\frac{1}{1+r}\right)^{j}\left[\tau_{t+j}-g_{t+j}\right]
$$

As we noted, since $B_{t-1}+M_{t-1}$ are predetermined nominal variables and the sum on the right hand side is the result of 'disjoint' public policy decisions, there is little hope that for any given price-level the requirement that (2.34) nonetheless 
hold in equilibrium is satisfied. Is there a contradiction here? If instead we view (2.34) as an equation itself defining the equilibrium price-level, then the FTPL argues there is no contradiction. Indeed, some fiscal theory writers argue that this approach to price-level determination resolves an issue of some importance in monetary theory-the indeterminacy of the price-level under an interest rate rule (see Woodford, 1996).

\subsection{A Specific Example}

Using the model developed above, we exposit a simple example of the FTPL based on McCallum (2001). Let us continue with our simple endowment economy, in which the agent receives $y$ units of nonstorable output each period. The government confiscates a given amount each period, $\tau_{t}-g>0$ where $\tau$ is also assumed constant through time. We assume a period utility function as in the previous section. In this case, the Euler equation for consumption yields,

$$
\left(1+i_{t}\right)=(1+\delta) \frac{P_{t+1}}{P_{t}}
$$

The demand for money is, in turn, given by

$$
\frac{M}{P_{t}}=\chi C\left(\frac{1+i_{t}}{i_{t}}\right)
$$

where we have assumed a constant money stock for all $t$. Combining these two equations as we did in deriving (2.5), we find that the price-level evolves in the following way,

$$
P_{t+1}=(1+\delta)^{-1} P_{t}\left(1+\frac{P_{t} \chi C}{M-P_{t} \chi C}\right) .
$$

As we noted above, this equation, familiar in this class of models (see for example Brock, 1975 or Obstfeld and Rogoff, 1983), has a number of interesting properties. First it is unstable difference equation with fixed points at zero and at some positive level, $P^{*}$. For $P>P^{*}$, the price-level rises without bound, while for 
$P<P^{*}$, the price-level falls without bound. Some of these paths are usually ruled out as equilibria as they are taken to imply a breach of (2.19) above. ${ }^{16}$

Our assumptions mean that debt evolves in the following manner

$$
\frac{b_{t}}{1+r_{t}}=b_{t-1}+\left(g-\tau_{t}\right)
$$

However, as we saw above, this policy for the deficit implies a debt level that is inconsistent with the requirement that government meets a no-Ponzi requirement, itself driven by a similar consideration on the representative agent's optimal consumption programme. However, if real debt in this period were somehow to equal

$$
b_{t-1}=\frac{1+\delta}{\delta}\left(\tau_{t}-g\right)
$$

then it follows that debt would forever remain at this level. We return to this point shortly.

\subsection{A monetarist equilibrium}

That the above model supports a monetarist equilibrium is straightforward to see. First, note that in this case $P=P^{*}$. Then we have that $\left(1+i_{t}\right)=(1+\delta)$, and $M / P^{*}=\chi C(1+\delta) / \delta$. Notice, we have not used (2.39) in our construction of this equilibrium. Indeed, we have assumed that unstable debt processes are inadmissible: (2.39) would be no part of a fiscal authority's plan for the evolution of debt. McCallum also argues that such an equilibrium does not contradict our assumption that $\tau_{t}-g>0$. He argues that in such a situation it means that the fiscal authority must in effect be providing transfer payments to households so that the apparent surplus is being offset by transfer payments to the public.

\footnotetext{
${ }^{16}$ Although, McCallum (2001) argues that (2.19) above may not be the appropriate version of the no-Ponzi condition. We leave that issue to one side for present purposes.
} 
He concludes that the fiscal authority's primary surplus is constrained necessarily to equal zero.

\subsection{A FTPL equilibrium}

The fiscal theorists would identify an alternative equilibrium of the model. First note that we may rewrite (2.39) as,

$$
\frac{B_{t-1}}{P_{t}}=\frac{1+\delta}{\delta}\left(\tau_{t}-g\right) .
$$

The FTPL locates the equilibrium expression for the price-level in (2.40). ${ }^{17}$ Let this expression determine the initial price-level. Consequently, then, the evolution of the price level is again given by equation (2.37), and the path of prices is unrelated to the value of the money stock. Buiter (2001) refers to this example as a fiscal theory of the initial price-level.

Critics of the FTPL have generally adopted one of three approaches. First, some have argued that it is difficult to interpret real world data from the perspective of the fiscal theory. For example, Canzoneri, Cumby and Diba (1999) analyze the response, over the post-war period, of US Debt to an innovation in the federal government's budget balance. They find that debt responds negatively to the primary surplus and conclude that the post-war US data are most plausibly interpreted as consistent with a Ricardian regime. Looking at the 'reverse' response, Bohn (1998a) finds that US fiscal surpluses respond positively to debt. He interprets this as evidence that US fiscal policy has been sustainable and although he does not comment directly on the fiscal theory of the price level, his results are again consistent with "traditional" views.

Using a long-run of UK data covering the period 1705-1996, Janssen, Nolan and Thomas (2002) adopt a structural VAR approach modelling the long-run

\footnotetext{
${ }^{17}$ Recall that $\tau_{t}-g>0$. Note the criticism of Buiter mentioned below.
} 
relationships between money, debt and prices. They find, as in the shorter-run studies using US data, that debt leads surpluses, while the reverse does not hold. In addition they find that money leads prices but that the reverse does not hold. They argue that the Sargent and Wallace concerns appear unfounded in practice and that the FTPL may be hard to reconcile with the data.

Nevertheless many find these empirical exercises unpersuasive. Indeed some argue that the FTPL is an untestable theory. They point out that all data are equilibrium observations and since both Ricardian and non-Ricardian fiscal policies retain the PVBC as an equilibrium relationship there is no way using timeseries data to distinguish between regimes. ${ }^{18}$ Indeed episodic evidence shows how difficult it is test theories on long run data, particularly when such theories require the development of expectations of infinite sums. We illustrate with a simple example of the fiscal-monetary programme adopted by the British government during the Napoleonic Wars. ${ }^{19}$ Figure 1 shows the relationship between fiscal surpluses and price level adjustment to be complicated. During gold standard maintenance, persistent deficits had little or no relationship with the price level but following 1797, the fiscal deficits clearly lead the increase in the price level.

\footnotetext{
${ }^{18}$ The issue of the testability of the FTPL is taken up in Janssen, Nolan and Thomas (2002) and in Christiano and Fitzgerald (2001).

${ }^{19}$ We concentrate on the period 1780-1830 during which time a number of interesting experiments on fiscal-monetary programme were run. Government expenditure on the Napolenic Wars, 1793-1815, set the national debt to income ratio on a path which led to it rising from 1.6 in both 1780 and 1793 to as high as 2.7 in 1821, in fact this ratio has subsequently only been equalled in 1946. Great Britain fixed the price of Sterling in terms of gold in 1717 but adopted a rolling programme of temporary suspensions of the standard during the wars and the immediate postwar reconstruction period. This suspension of the gold standard was associated with monetary accommodation of public and private demand during which time annual commodity price inflation, which had averaged $0.5 \%$ from $1717-1792$, averaged over $3.5 \%$ from 1797 to inflationary peak in 1813 . Subsequently, the price level fell to approximately its prewar level by 1822. Sargent and Velde (1995) consider the myriad problems of French finance during this complicated period in detail. Gayer, Rostow and Schwartz (1953), mainly from British Parliamentary Papers, provide the data we used in compiling the graphs. Fetter (1965) provides a clear picture of the policy choices made in this period.
} 
But we note a sharp fall in the price level in 1814 some three years before the sequence fiscal deficits head to near zero in 1817. Figure 2 shows that there is some evidence to suggest that money led prices in the period leading up to gold standard suspension in 1797 but that towards the end of the Napoleonic Wars there was a clear adjustment of the price level prior to the reduction of Bank of England notes issued. We leave further analysis of this period to future work.

A second line of attack, forcefully pursued by Buiter $(1998,1999)$, is that the FTPL involves an unwarranted weakening of the government's present-value budget constraint. In requiring this to hold only in equilibrium, the FTPL enables the government to breach a fundamental requirement of a market economy: all agents must respect their budget constraints. He argues that the FTPL gives rise to certain anomalies which mean that the FTPL has to be "switched off" arbitrarily if the pice-level is to be determinate. Here we give two examples from Buiter (1999). Consider what happens if there is no nominal debt, and all government liabilities are real (i.e., indexed linked). In that case there can be no fiscal theory of price determination. ${ }^{20}$ Buiter also argues that there is no reason for us to expect under the FTPL that both sides of (2.35) have the same sign. However, the pricelevel cannot be negative, and so he argues that once again the FTPL needs to be arbitrarily switched off.

A final line of criticism of the FTPL has been pursued by McCallum (2001). He argues that the FTPL involves an implausible/unattractive equilibrium selection in that bubble solutions are favoured over the minimum state variable (MSV), or fundamentals, solution. He argues that since in the model under consideration the money stock is constant (there is no relevant state variable), and since the price-level is a jump variable $\left(P_{t}=\phi\left(E_{t} P_{t+1}\right)\right.$, the MSV solution is of the following form, $P_{t}=c$, where $c$ denotes some constant value. In that case one can show

\footnotetext{
${ }^{20}$ The same is true if all debt is foreign-currency denominated.
} 
that $P_{t}=P^{*}$. He goes on to argue that whilst the fiscalist equilibrium is logically coherent it depends on the introduction of an extraneous state variable, that is a solution essentially of the form, $P_{t}=\phi\left(P_{t-1}\right) \cdot{ }^{21}$

\section{Fiscal policy and Interest Rate Bounds}

Much of the literature that we have touched on has characterized monetary policy as the evolution through time (and across states) of the money stock. In addition, it has tended to assume that prices are flexible. These assumptions have been useful in developing many of the key points outlined above. However, a plausible case can be made that neither assumption is particularly realistic, so it is an interesting exercise to investigate what may happen if we adopt alternative assumptions. In the next section we characterize monetary policy as a sequence of interest rates and we assume that prices are to some extent inflexible. It turns out that adopting this perspective does offer new insights. In section 7-10, we shall characterize monetary policy in just these terms. We identify the sorts of bounds required on interest rates to ensure fiscal solvency. We shall find this information of some use in sections 7 and beyond when we formulate fiscal rules for the purpose of simulation.

There has been considerable recent interest in characterizing monetary policy in terms of the choice of the (optimal) interest rate sequence. As Taylor (1999) demonstrates, it seems that monetary policy can be usefully characterized as a feedback rule for the short term nominal interest rate. ${ }^{22}$ In addition, Woodford (1997) demonstrates that modelling the monetary authority as controlling the

\footnotetext{
${ }^{21}$ This debate is on going. While Woodford (2001) rejects this line of criticism, McCallum (2002) has recently enlarged on his concerns to argue that the fiscalist equilibrium is not learnable, in the sense of Evans and Honkapohja (2001).

${ }^{22}$ As well as outlining this principle, Taylor (1999) also outlines the general scope of the finding through time and across several countries.
} 
short-term nominal interest rate is consistent with a determinate (at least, locally) unique rational expectations equilibrium.

In the next section, we analyze the relation between interest rates and fiscal variables, within the confines of the public sector's present-value budget constraint. We analyze a number of simple scenarios for the evolution of fiscal policy and derive the corresponding implications for the interest rate. The PVBC makes clear that monetary and fiscal policy are closely linked, and perhaps more so than one might conclude from viewing monetary policy as simply control over the money supply. Whether this implies any practical constraint for monetary policy is, however, an open issue - the restrictions we derive on the interest rate imply bounds on the interest rate sequence possibly far out in the future.

\section{Budget Constraints and Interest Rates}

We continue to work within a deterministic framework. Financial wealth takes one of two forms: money, which earns no interest, and one-period nominal bonds which do earn interest. ${ }^{23}$ We may think of a fiscal authority setting fiscal variables (taxes and debt, given expenditure), and monetary authority determining the path for the interest rate. The seigniorage sequence determined as a result of the interest rate sequence is assumed to be determined endogenously (via a money demand equation which we do not explicitly model). As before, the one-period public sector flow budget constraint is given by:

$$
\frac{B_{t}}{\left(1+i_{t}\right)}=B_{t-1}+P_{t}\left(G_{t}-T_{t}\right)-\left(M_{t}-M_{t-1}\right) \text {. }
$$

$B_{t-1}$ is the nominal quantity of debt issued last period, and maturing this period, $i_{t}$ is the nominal interest rate between period $t$ and $t+1, P_{t}$ is the aggregate

\footnotetext{
${ }^{23}$ The following analysis does not incorporate the behavior of the private sector, as the main points can be made without doing so.
} 
price level, $\left(G_{t}-T_{t}\right)$ is the real primary deficit in period $t$, and $\left(M_{t}-M_{t-1}\right)$ is seigniorage raised in period $t$. A central assumption is that the monetary-fiscal sequences avoid Ponzi schemes, ${ }^{24}$ such that,

$$
\lim _{T \rightarrow \infty} B_{t+T}\left(\prod_{j=0}^{T}\left(1+i_{t+j}\right)\right)^{-1}=0 .
$$

What we found in section 2 was that a condition similar to (4.2) is sufficient to ensure that the PVBC is satisfied. This condition ensures that for a given the level of outstanding liabilities at the start of any time period the ensuing intertemporal sequence of net surpluses plus seigniorage is sufficient to meet those liabilities.

We shall analyze fiscal rules (or regimes) of the following form:

$$
T_{t}=\lambda_{t} G_{t}-\frac{\left(M_{t}-M_{t-1}\right)}{P_{t}}+\gamma \frac{B_{t-1}}{P_{t}}
$$

where $T_{t}$ denotes tax revenue generated in period $t$. Fiscal policy is characterized by the sequence $\left\{\left(\lambda_{t+s}, \gamma_{t+s}\right)\right\}_{s=0}^{T}$. In other words, we may think of fiscal policy as determining the amount of debt retired, and the size of the primary deficit (i.e., $\gamma$ and $\left.\left(1-\lambda_{t+s}\right) G_{t+s}\right)$. We assume that $\gamma \in(0,1)$, is fixed for all time. This is a useful assumption that makes it more easy to characterize the kind of restrictions on the interest rate and $\gamma$ that we are seeking. Finally, again for simplicity, we assume that seigniorage revenue is rebated lump sum to the private sector. The particular fiscal rules that we analyze will then be indexed simply by restrictions on the sequence $\left\{\lambda_{t+s}\right\}_{s=0}^{T}$.

Equation (4.2) is a very general statement of the kind of restrictions we require on monetary and fiscal policy. However, we can re-write it in a manner more

\footnotetext{
${ }^{24}$ As we noted before, the no-Ponzi game restriction is consistent with optimal private sector behaviour. O'Connell and Zeldes (1988) demonstrate that no rational individual will hold the liabilities of a government that attempts to run a Ponzi game. That is because the welfare of any individual holding such government debt for any period will be strictly lower than under an alternate feasible consumption programme.
} 
applicable to the class of fiscal rules under consideration. First, since $\gamma>0$, the fiscal authority, looking forward from any time $t$, will always do enough to repay the outstanding debt in existence at the start of time $t$, that is

$$
\lim _{T \rightarrow \infty}(1-\gamma)^{T+1} B_{t-1}=0 .
$$

Consequently, for monetary and fiscal policy to be consistent with fiscal solvency there must be a sufficient amount of (discounted) net surpluses looking forward from date $t$. Therefore $\lim _{T \rightarrow \infty} B_{t+T}\left(\prod_{j=0}^{T}\left(1+i_{t+j}\right)\right)^{-1}=0$ if and only if

$$
\sum_{s=0}^{T}\left[\left\{\prod_{j=0}^{s-1}\left(1+i_{t+j}\right)\right\}^{-1}(1-\gamma)^{T-s}\left(1-\lambda_{t+s}\right) P_{t+s} G_{t+s}\right] \rightarrow 0
$$

\subsection{A Balanced Budget Regime}

The first regime we analyze is one in which the government is not permitted (or does not desire) to deviate from a zero balance on the primary deficit. Some debt was issued in the past, and the government is committed to repaying that at a constant rate, $\gamma$. Fiscal policy is simply the sequence $\{(\lambda, \gamma)\}_{s=0}^{T}$ with $\lambda=1$ and $0<\gamma<1, \quad \forall s$. Monetary policy is the sequence of one period decisions denoted by $\left\{i_{t+s}\right\}_{s=0}^{T}$. In period $t$ the tax yield is given by (4.5):

$$
T_{t}=G_{t}-\frac{\left(M_{t}-M_{t-1}\right)}{P_{t}}+\gamma \frac{B_{t-1}}{P_{t}} .
$$

Using (4.5) in (4.1) reveals that

$$
\frac{B_{t}}{\left(1+i_{t}\right)}=(1-\gamma) B_{t-1}
$$

Iterating on this expression demonstrates that such a fiscal rule satisfies the no Ponzi game condition independently of monetary policy, that is the sequence of interest rates, since 


$$
\lim _{T \rightarrow \infty} B_{t+T}\left(\prod_{j=0}^{T}\left(1+i_{t+j}\right)\right)^{-1}=\lim _{T \rightarrow \infty}(1-\gamma)^{T+1} B_{t-1}=0 .
$$

To confirm this result, set $\lambda=1 \forall s$ in equation (4.4). In this case, there is no linkage between fiscal variables and the interest rate. Outstanding debt will become vanishingly small in finite time, and there is no constraint on monetary policy.

\subsection{Permanent Deficits}

We now go to the opposite extreme and enquire as to the feasibility of permanent deficits. The existence of a permanent deficit may be taken to imply that $\lambda \in(0,1), \forall t$. We continue to assume that there is a lower bound on taxes determined by the the debt repayment parameter $\gamma$. The fiscal rule is now:

$$
T_{t}=\lambda G_{t}-\frac{\left(M_{t}-M_{t-1}\right)}{P_{t}}+\gamma \frac{B_{t-1}}{P_{t}} .
$$

Substituting (4.8) into (4.1) yields

$$
\frac{B_{t}}{\left(1+i_{t}\right)}=(1-\gamma) B_{t-1}+(1-\lambda) P_{t} G_{t}
$$

The public sector is now running a deficit in every period. This policy is sustainable just if the following expression goes to zero in the limit:

$$
\begin{aligned}
& B_{t+T}\left(\prod_{j=0}^{T}\left(1+i_{t+j}\right)\right)^{-1}=(1-\gamma)^{T+1} B_{t-1}+ \\
&(1-\lambda) \sum_{s=0}^{T}\left[\left\{\prod_{j=0}^{s-1}\left(1+i_{t+j}\right)\right\}^{-1}(1-\gamma)^{T-s} P_{t+s} G_{t+s}\right] .
\end{aligned}
$$


The analysis in Section 4.1 demonstrates that we require the second term on the right-hand side of this expression to converge to zero. As (4.10) is a special case of (4.4) it will be convenient to make some simplifying assumptions. A useful special case is where the sequence of nominal government expenditures is fixed:

$$
(1-\lambda) P_{t+s} G_{t+s}=(1-\lambda) \overline{P G} \quad \forall s
$$

Now substitute (4.11) into (4.10) to see that the second expression on the right hand side of (4.10) may be written as

$$
(1-\lambda) \overline{P G} \sum_{s=0}^{T}\left[\left\{\prod_{j=0}^{s-1}\left(1+i_{t+j}\right)\right\}^{-1}(1-\gamma)^{T-s}\right] .
$$

This expression brings out clearly the potential tension between monetary and fiscal policy. Given the rate of retirement of outstanding debt $(\gamma)$, it is left to monetary policy to ensure convergence of this expression to zero. On the other hand, if the monetary authority had a stronger commitment technology we would regard (4.12) as determining a bound on $\gamma$. An interesting example of the implications for monetary policy is where interest rates are set at the level given in equation (4.13)

$$
i_{t+s}=\left\{(1-\gamma)^{-2}-1\right\} \quad \forall s \geq 0
$$

If monetary policy follows this path then expression (4.12) can be written as

$$
(1-\gamma)^{T} \sum_{s=t}^{T}\left[(1-\gamma)^{s-t}(1-\lambda) \overline{P G}\right]
$$

where the expression in square braces converges to

$$
\frac{1-\lambda}{\gamma} \overline{P G}
$$


Consequently, as $T \rightarrow \infty$ expression (4.14) tends to zero. Although it is clear that (4.13) is not unique, ${ }^{25}$ in the spirit of McCallum (1984) we find that (4.13) is a sufficient condition for permanent deficits to be a feasible fiscal policy. But, and more importantly, we find that permanent fiscal deficits effectively place an upper bound on the sequence of feasible interest rates and so do not imply complete 'separability' in the feasible set of monetary and fiscal choices. The result here is intuitive insofar as the bound increasingly constrains the interest rate sequence as the fiscal authority's chosen rate of debt retirement becomes smaller.

\section{Tax Smoothing and Inflexible Prices}

We have shown that the separability of monetary from fiscal policy is not complete under a regime of permanent fiscal deficits. In this section we illustrate the generality of this conclusion.

The assumption of completely fixed prices is not crucial to our arguments. What is critical, as we now make explicit, is that, for a given value of $\gamma$, the monetary authority needs sufficient control over the real short-term interest rate. We continue to assume that government expenditure is constant. Rewriting solvency condition (4.4) in real terms yields

$$
(1-\lambda) \bar{G} \sum_{s=0}^{T}\left[\left\{\prod_{j=0}^{s-1} \frac{\left(1+\pi_{t+1+j}\right)}{\left(1+i_{t+j}\right)}\right\}(1-\gamma)^{T-s}\right] .
$$

As in the previous example, the expression in square braces must tend to zero in the limit if the requirements of fiscal solvency are to be met. Expression (5.1) can

\footnotetext{
${ }^{25}$ There are a number of ways to see this non-uniqueness. Perhaps the most obvious is to note that if $i_{t+s}=\left\{(1-\gamma)^{-2}-1\right\} \forall s \geq 0$ is a feasible equilibrium sequence then so too must be $i_{t+s}=\left\{[2(1-\gamma)]^{-2}-1\right\} \forall s \geq 0$.
} 
usefully be re-written as

$$
(1-\lambda)(1-\gamma)^{T} \bar{G} \sum_{s=0}^{T}\left[\left\{\prod_{j=0}^{s-1} \frac{\left(1+\pi_{t+1+j}\right)}{\left(1+i_{t+j}\right)}\right\}\left(\frac{1}{1-\gamma}\right)^{s}\right] .
$$

A sufficient condition for this expression to reach zero in the limit is simply that the term in square braces is convergent, as opposed to having a zero limiting value. ${ }^{26}$ It can then be shown that this will be the case when the following requirement is (eventually) met infinitely often: ${ }^{27}$

$$
i_{s}-\pi_{s+1}<\gamma \quad \forall s \geq T
$$

This expression has a very obvious interpretation in that it requires that the fiscal authority must eventually repay a sufficient portion of the debt each period. ${ }^{28}$ An alternative interpretation, is that the debt retirement schedule places an upper bound on the feasible real interest rate sequence.

\subsection{Tax Smoothing}

Permanent zero balances or permanent deficits are clearly extreme cases and obvious, more realistic, intermediate cases present themselves. For example, consider a deficit in period zero that is declining steadily through time. Such a policy may be viewed as a simple form of tax-smoothing. That is consider a deficit $D_{t}=\rho D_{t-1}$, where $\rho>1$ and where $D_{t} \equiv(1-\lambda) P_{t} G_{t}$. Then one can show that a condition analogous to (5.3) occurs:

$$
(1-\rho)+i_{s}-\pi_{s+1}<\gamma \quad \forall s \geq T .
$$

\footnotetext{
${ }^{26}$ See Rudin (1976), Theorem 3.3(c), page 49.

${ }^{27}$ We are essentially drawing on d'Alembert's ratio test. This says that for a convergent series: lim sup $\left|a_{n+1} / a_{n}\right|<1$. In the text, however, we are unwinding the unstable roots forward to ensure convergence.

${ }^{28}$ Actually this expression is an approximation, since we ignore the cross term: $\left[\left(p_{t+1} / p_{t}\right)-1\right] \times \gamma$
} 
Expression (5.4) tells us that under a regime in which the deficit is temporary but persistent the constraint on monetary policy is clearly eased, as compared to one where it is permanent, but that it is not entirely absent either.

\section{Some Conclusions Concerning Budgetary Arithmetic}

The results in this section compliment those of Sargent and Wallace (1981) and especially McCallum (1984). The latter showed that incorporating the interest burden into the arithmetic of fiscal solvency is important for the independence of monetary policy. However, if instead we view monetary policy as control of the short term real interest rate, the constraint imposed on monetary policy by a permanent deficit takes the form of an upper bound on the interest rate sequence. And even under less extreme fiscal policies, such as a temporary but persistent deficit, monetary conduct may be hampered. This latter result may also shed some light on why some monetary policy makers, such as at the European Central Bank, may support strict controls on the fiscal policies of member states. That said, it is also the case that these constraints on monetary policy may not be quantitatively that large. To the extent that the solvency requirements analyzed above require interest rates to be sufficiently accommodative eventually, the pressures may be more apparent than real. Nevertheless, our analysis must be regarded as somewhat preliminary as we have not nested our budgetary arithmetic in a complete dynamic general equilibrium model. In the next section, we shall do just that, and some of the implications of the foregoing section will be useful. 


\section{A Model for Business Cycle Analysis Under Ricardian Fiscal-Monetary Regimes}

So far our main concern has been with the constraints which monetary and fiscal policy can impose upon one another by virtue of the PVBC. That reflects the dominant concern in the literature which followed Sargent and Wallace (1981). And indeed those concerns have been influential in policy design. The Pact for Stability and Growth which governs those countries which are part of the Eurozone is in large part, it seems, motivated by concerns that fiscal policy could otherwise distort monetary policy decisions. However, these constraints could also impose costs on these economies. Having lost the ability to set monetary policy with regard to domestic considerations, it may appear desirable to retain some flexibility in setting fiscal policy. Indeed, the desirability of a flexible fiscal response goes beyond the countries of the Euro-area.

In this and the following sections we present a prototype model in which both monetary and fiscal policy are feasible instruments with which to stabilize the economy. As regards fiscal policy, the model in some sense lies between the traditional Ricardian-type fiscal analyses (as in Sargent and Wallace, 1981), and the new fiscal theory of the price-level. It shares with the literature growing out of the Sargent and Wallace tradition an insistence that the government budget constraint be met for all feasible price and interest rate sequences. In our set up that will mean that the price-level or inflation rate will be determined without reference to the issue of fiscal solvency. Nevertheless, it shares with the fiscal theory a recognition that there may well be wealth effects associated with government deficits, although the catalyst for these wealth effects will be somewhat different to the fiscal theory.

The model is constructed around a finite horizon model, following Yaari (1965) and Blanchard (1985). We extend this framework in a number of important 
directions. First following Cardia (1991) and Chadha and Janssen and Nolan (2001) and Chadha and Nolan (2002b) we translate the model into discrete time. We incorporate an imperfectly competitive production technology, to motivate the existence of sticky prices. A similar model in continuous time is developed by Leith and Wren-Lewis (2000) to analyze the joint requirements on monetary and fiscal policy that might be required for control of inflation to be possible. Like the latter authors, we model price stickiness in the manner of Calvo (1983), in what has become something of a benchmark for sticky-price models, (see Woodford, 1997). The utility function for the representative agent, $j$, is given by

$$
V_{0}=E_{0} \sum_{t=0}^{\infty}\left\{\left(\frac{1}{1+\delta}\right)^{t}\left(\frac{1}{1+\lambda}\right)^{t} U\left(C_{t}^{j}, \frac{M_{t}^{j}}{P_{t}}, L_{t}^{j}\right)\right\} .
$$

Here $\delta$ is the subjective discount rate and $\lambda$ is the probability of death. We assume that both these parameters are constant. As we demonstrate in an appendix, this set up is consistent with the expected remaining lifetime of the agent being equal to $\lambda^{-1}$. Because of this the model is sometimes dubbed the 'perpetual youth' model. We make the usual assumptions on the shape of the utility function. Expected utility is maximized subject to a sequence of per period budget constraints,

$$
P_{t} C_{t}^{j}+M_{t}^{j}+\frac{B_{t}^{j}}{\left(1+i_{t}\right)} \leq(1+\lambda) M_{t-1}^{j}+(1+\lambda) B_{t-1}^{j}+P_{t} Y_{t}^{j}-T_{t}^{j}
$$

where, $P_{t} C_{t}^{j}=\int_{0}^{1} \int_{0}^{1} p_{t}(k, z) c_{t}^{j}(k, z) d z d k$, and $P_{t} Y_{t}^{j}=\int_{0}^{1} \int_{0}^{1} p_{t}(j, z) y_{t}(j, z) d z$, and where (7.2) holds for all $t \geq 0$, and in each state of nature. Here $c_{t}^{j}(k, z)$ denotes the representative agent's consumption of good $(k, z)$ where $z$ indexes agents in the economy. Similarly, $y_{t}(j, z)$ indicates the amount of output produced by the agent. This formulation follows Woodford (1997) and assumes that each agent is a monopoly supplier of all goods that it supplies, while each agent also consumes 
a basket of all goods. In this way, we partial out any wealth effects that might otherwise have occurred due to price rigidity. ${ }^{29} B_{t}^{j}$ denotes the bond portfolio, $M_{t}^{j}$ denotes money balances, $P_{t}$ is the aggregate price-level, $Y_{t}$ denotes non-financial income and $T_{t}^{j}$ denotes lump sum taxes. The evolution of wealth is given by

$$
W_{t}^{j}=(1+\lambda) M_{t-1}^{j}+(1+\lambda) B_{t-1}^{j}
$$

where we assume, following, Blanchard (1985) that perfect capital markets return all financial wealth to the population as windfall dividends in the event of death. Combining (7.2) and (7.3), we get that

$$
W_{t}^{j}=\left(\frac{1}{1+i_{t}}\right)\left(\frac{1}{1+\lambda}\right) E_{t} W_{t+1}^{j}+P_{t} C_{t}^{j}-P_{t} Y_{t}^{j}+\frac{i_{t}}{1+i_{t}} M_{t}^{j}
$$

which implies if $\lim _{T \rightarrow \infty}\left(\frac{1}{1+\lambda}\right)^{T} E_{0} \prod_{j=0}^{T-1}\left(1+i_{t+j}\right)^{-1} W_{t+T}^{j} \rightarrow 0$, that

$$
W_{t}^{j}=-E_{t} \sum_{s=t}^{\infty} \prod_{j=t}^{s-1}\left\{\left(\frac{1}{1+i_{t+j}}\right)\left(\frac{1}{1+\lambda}\right)^{s-t}\left[P_{s}\left(C_{s}^{j}-Y_{s}^{j}\right)+T_{s}^{j}+\frac{i_{s}}{1+i_{s}} M_{s}^{j}\right]\right\}
$$

We note that both (7.4) and (7.5) reflect now the probability faced by the agent of not being alive in any subsequent period. The simple way we have incorporated this effect means that the probability of death serves merely to act to increase

\footnotetext{
${ }^{29} \mathrm{By}$ not modelling factor markets and the corporate sector explicitly, we can develop the key aggregate equations with a minimum of fuss. However, in adopting this approach we gloss over some important aggregation issues present in the overlapping generations framework. For example different cohorts are at different stages of their life-cycle and hence consumption and saving are not constant across cohorts. Consequently different cohorts have different stocks of wealth, and hence different marginal utility of consumption. And because of this, optimal labour supply will also differ. If we now consider the effects of shocks that affect currently alive cohorts but perhaps not those yet to be born, the situation seems very complex.

However, in practice the key problem centres around the labour supply function-most other elements are straightforward. And with respect to the labour supply function if we assume that our utility function is a log specification that complication also disappears. For a more detailed discussion, see Chadha and Nolan (2002e) and an appendix to that paper, available on request.
} 
the effective rate of discount. Consumption is defined over the Dixit-Stiglitz aggregator function,

$$
C_{t}^{j} \equiv\left[\int_{0}^{1} \int_{0}^{1} c_{t}^{j}(k, z)^{\frac{\theta-1}{\theta}} d z d k\right]^{\frac{\theta}{\theta-1}},
$$

with the aggregate price-level defined accordingly as:

$$
P_{t} \equiv\left[\int_{0}^{1} \int_{0}^{1} p_{t}(j, z)^{1-\theta} d z d j\right]^{\frac{1}{1-\theta}} .
$$

If we let $\left\{\mu_{s}\right\}_{s=t}^{\infty}$ denote the sequence of positive undetermined multipliers, we may form the Lagrangian function:

$$
\begin{gathered}
\mathfrak{L}=E_{0} \sum_{t=0}^{\infty}\left\{\left(\frac{1}{1+\delta}\right)^{t}\left(\frac{1}{1+\lambda}\right)^{t} U\left(C_{t}^{j}, \frac{M_{t}^{j}}{P_{t}}, L_{t}^{j}\right)\right\}+ \\
E_{0} \sum_{t=0}^{\infty}\left\{\left(\frac{1}{1+\delta}\right)^{t} \mu_{t}^{j}\left[(1+\lambda) M_{t-1}^{j}+(1+\lambda) B_{t-1}^{j}+P_{t} Y_{t}^{j}-T_{t}^{j}-\frac{B_{t}^{j}}{\left(1+i_{t}\right)}-M_{t}^{j}-P_{t} C_{t}^{j}\right]\right\} .
\end{gathered}
$$

\subsection{The demand side}

The first-order conditions of the representative agent from any cohort are familiar, except that we now see the effect of the probability of death. At each date and in each state we have that an interior optimum will be characterized by, amongst other conditions, equations (7.9), (7.10) and (7.11):

$$
\begin{gathered}
\left(\frac{1}{1+\lambda}\right)^{t} U_{c}^{\prime}\left(C_{t}^{j}, M_{t}^{j} / P_{t}, L_{t}^{j}\right)=\mu_{t}^{j} P_{t}, \\
\left(\frac{1}{1+\lambda}\right)^{t} U_{M}^{\prime}\left(C_{t}^{j}, M_{t}^{j} / P_{t}, L_{t}^{j}\right) / P_{t}+\left(\frac{1}{1+\delta}\right)(1+\lambda) E_{t} \mu_{t+1}^{j}=\mu_{t}^{j},
\end{gathered}
$$




$$
\left(\frac{1}{1+\delta}\right) E_{t} \mu_{t+1}^{j}(1+\lambda)\left(1+i_{t}\right)=\mu_{t}^{j}
$$

These three expressions can be combined and yield immediately the following two expressions.

$$
\begin{gathered}
\frac{1}{1+\delta} \frac{E_{t} U^{\prime}\left(C_{t+1}^{j}\right)}{P_{t+1}}\left(1+i_{t}\right)=\frac{U^{\prime}\left(C_{t}^{j}\right)}{P_{t}}, \\
\frac{U_{M}^{\prime}\left(C_{t}^{j}, M_{t}^{j} / P_{t}, L_{t}^{j}\right)}{U_{c}^{\prime}\left(C_{t}^{j}, M_{t}^{j} / P_{t}, L_{t}^{j}\right)}=\frac{i_{t}}{1+i_{t}} .
\end{gathered}
$$

Despite the probability of death we see no tilting of consumption towards the present, and no reduction in the demand for money, as one might have supposed. In fact, given our assumptions on the operation of the capital/equity markets and the money market this makes perfect sense. Any windfall gain from agents dying and leaving unconsumed real resources (either in the form of 'unspent' bonds or money) are simply passed on to those agents left alive. However, those agents, in turn, face an excess interest premium (in order to ensure a zero profit equilibrium). These two effects cancel.

Finally, optimality requires that the flow budget constraint holds with equality in each period and in each state, and the following no-Ponzi finance condition be satisfied:

$$
\lim _{T \rightarrow \infty}\left(\frac{1}{1+\lambda}\right)^{T} E_{0}\left\{\prod_{j=0}^{T-1}\left(1+i_{t+j}\right)\right\}^{-1} W_{t+T} \rightarrow 0 .
$$

Again this is a familiar expression, save for the inclusion of the probability of death factor.

\subsection{The supply side}

Agent's are assumed to meet demand at the posted price, whether or not prices have been changed in the current period. We follow Calvo (1983), then, and 
many subsequent analysts and assume that when a price is set in period $t$ it will remain at that nominal level with probability, $\alpha(0 \leq \alpha<1)$. More generally, an agent that re-prices some part of his or her output this period faces the probability $\alpha^{k}$ of having to charge the same price in $k$-periods time. We consider the repricing by agent $j$ of one good, $z$. We demonstrate that the optimal price is a function of aggregate economy wide variables only. As a consequence we can easily aggregate across all goods in our economy, given (7.7). It will be convenient now to introduce a specific functional form for our utility functional and we shall assume the following $U\left(C_{t}^{j}, \frac{M_{t}^{j}}{P_{t}}, L_{t}^{j}\right) \equiv \log C+\log (M / P)-\int_{0}^{1} \varpi\left[y_{t}(j, z)\right] d z$. This will also be the functional form assumed in our simulation results reported in section 10. $\int_{0}^{1} \varpi\left[y_{t}(j, z)\right] d z$ denotes the marginal disutility of supplying labour across all $z$ goods. For any individual good, then, it follows that the optimal level of $p(z)$, say, $p_{t}^{*}$ will be that which maximizes the following function

$$
\Phi=E_{0} \sum_{k=0}^{\infty}\left(\alpha \beta^{\prime}\right)^{k}\left\{\mu_{t+k} p(z)\left(\frac{p(z)}{P_{t+k}}\right)^{-\theta} Y_{t+k}-\varpi\left[\left(\frac{p(z)}{P_{t+k}}\right)^{-\theta} Y_{t+k}\right]\right\} .
$$

So calculating $\frac{\partial \Phi}{\partial p(z)}$ it is easy to show that

$$
\begin{aligned}
& E_{0} \sum_{k=0}^{\infty}\left\{\left(\alpha \beta^{\prime}\right)^{k} \mu_{t+k}\left(\frac{p(z)}{P_{t+k}}\right)^{-\theta} Y_{t+k} p(z) \frac{1-\theta}{\theta}\right\}= \\
& \quad-E_{0} \sum_{k=0}^{\infty}\left\{\left(\alpha \beta^{\prime}\right)^{k} \mu_{t+k}\left(\frac{p(z)}{P_{t+k}}\right)^{-\theta} Y_{t+k} \varpi^{\prime}\left[\frac{\left(\frac{p(z)}{P_{t+k}}\right)^{-\theta} Y_{t+k}}{\mu_{t+k}}\right]\right\},
\end{aligned}
$$

and hence finally that,

$$
p_{t}^{*}=\frac{\theta}{\theta-1} \frac{E_{0} \sum_{k=0}^{\infty}\left\{\left(\alpha \beta^{\prime}\right)^{k} \mu_{t+k}\left(\frac{p(z)}{P_{t+k}}\right)^{-\theta} Y_{t+k} \varpi^{\prime}[\cdot]\right\}}{E_{0} \sum_{k=0}^{\infty}\left\{\left(\alpha \beta^{\prime}\right)^{k} \mu_{t+k}\left(\frac{p(z)}{P_{t+k}}\right)^{-\theta} Y_{t+k}\right\}} .
$$


Here $\mu_{t+k}$ is a measure of aggregate marginal utility, and $\beta=\beta^{\prime}(1+\lambda)^{-1}$. Expression (7.16) indicates that the optimal price is a function of expected future demand and cost conditions. It follows that the evolution of the aggregate pricelevel is given by

$$
P_{t}=\left[(1-\alpha) p_{t}^{* 1-\theta}+\alpha P_{t-1}^{1-\theta}\right]^{1 /(1-\theta)} \cdot 30
$$

\subsection{Aggregation}

Our aggregator function is a discrete time analogue of Blanchard (1985). See Chadha, Janssen and Nolan (2001) and Chadha and Nolan (2002) for a detailed description of our discretization of the Blanchard (1985) model.

First we note that the size of the cohort born each period is given by

$$
\left(\frac{\lambda}{1+\lambda}\right)\left(\frac{1}{1+\lambda}\right)^{t}
$$

Naturally death means that the size of the cohort decreases monotonically with time, and the sum of all currently alive cohorts is equal to unity, that is ${ }^{31}$

$$
\frac{\lambda}{1+\lambda} \sum_{j=-\infty}^{t}\left(\frac{1}{1+\lambda}\right)^{(t-j)}=1 .
$$

This makes aggregating the model, for the most part, straightforward. In Chadha and Nolan (2002e) we provide more detail on these calculations. In particular, for any variable $x_{t}^{a}$ it follows that,

$$
x_{t}^{a}=\frac{\lambda}{1+\lambda} \sum_{s=-\infty}^{t}\left(\frac{1}{1+\lambda}\right)^{t-s} x_{s, t} .
$$

\footnotetext{
${ }^{30} \mathrm{~A}$ strict interpretation of our set-up implies then that a proportion of each cohort will never get to price some of its output. This is an artifact of combining a yeoman-farmer with a probability of death set-up. If we modelled the corporate sector separately, as in Chadha and Nolan (2002e), this anomaly disappears. Consequently, we ignore it in what follows. Alternatively, one may think of the newly born agents inheriting the price tags of the currently expiring agents.

${ }^{31}$ We outline in more detail in an appendix the construction of our discrete approximation to the continuous exponential density.
} 
The derivation of aggregate consumption dynamics is slightly more involved and we go through that derivation in detail in an appendix. We show that aggregate consumption dynamics are given by the following expression,

$$
E_{t} P_{t+1} C_{t+1}=\left(1+i_{t}\right) \beta P_{t} C_{t}-\lambda \phi E_{t} W_{t+1}
$$

In the infinite horizon case (where $\lambda=0$ ) this expression is simply $E_{t} P_{t+1} C_{t+1}=$ $\left(1+i_{t}\right) \beta P_{t} C_{t}$, the familiar consumption Euler equation. This equation describes how aggregate consumption evolves through time-and importantly we see that temporal variations in financial wealth plays no part in determining contemporaneous consumption. In other words, in the absence of distortionary taxation, liquidity constraints (or other financial frictions), deviations from rational expectations and in the presence, as we make clear below, of a Ricardian fiscal policy (and other ingredients which cook up Ricardian Equivalence, see Barro, 1974), we see that it makes no odds to the economy whether taxes are raised now or in the future. Agents will consume out of their present value of net wealth, and since lower taxes now resulting in higher taxes in the future does not alter the present value of net wealth, their will be no leverage for fiscal policy to operate in this model via the level of outstanding government debt. However, in the case of finite horizons, $\lambda \neq 0$ variations in the temporal allocation of taxes are not 'neutral'. Net wealth is affected by the time profile of taxes. In our simple set-up, that is essentially because the probability of a currently alive cohort facing a given tax bill has fallen and hence the consumption set has expanded.

\section{Monetary and Fiscal Policy}

We shall in general consider policymakers as setting the per period interest rate and taxes in order to stabilize both output and inflation. That is we are envisaging 
policy rules of the following sort:

$$
i_{t}=\phi(i)\left[Y_{t}, \pi_{t}, E_{t} \pi_{t+1}, i_{t-1}\right]
$$

and

$$
T_{t}=\phi(T)\left[G_{t}, \gamma B_{t-1}\right]
$$

where $i_{t}$ is the short nominal interest rate set in period $t, Y_{t}$ is real aggregate output, $\pi_{t}$ is the inflation rate in period $t$, and $T_{t}$ is the per period lump sum taxes. While the monetary rule is fairly standard the rule for tax needs some explanation. We shall assume that the process for government expenditure is essentially exogenous. We shall further assume that the fiscal authority sets taxes in response to the level of contemporaneous government expenditure and crucially, the level of outstanding debt at the start of the period. The parameter $\gamma$ indicates the proportion of debt that is retired each period. We shall assume that seigniorage is remitted lump-sum to the private sector.

\section{The Government Budget}

As we saw above in Sections 4 to $6 \gamma$ is a key parameter in ensuring fiscal policy is Ricardian. Here we give another example in this vein for the case of a fiscal rule that we actually use in our simulations below. Recall that the period public sector budget constraint, reproduced here for convenience, may be written as,

$$
\frac{B_{t}}{\left(1+i_{t}\right)}=B_{t-1}+P_{t}\left(G_{t}-T_{t}\right)-\left(M_{t}-M_{t-1}\right)
$$

The rule for taxes mentioned above is given by

$$
T_{t}=\chi_{t} G_{t}-\frac{\left(M_{t}-M_{t-1}\right)}{P_{t}}+\gamma \frac{B_{t-1}}{P_{t}} .
$$


Together these two equations imply that real debt will evolve in the following manner,

$$
\frac{b_{t}}{1+r_{t}}=(1-\gamma) b_{t-1}+\left(1-\chi_{t}\right) G_{t}
$$

So we call $\left(1-\chi_{t}\right) G_{t}$ the per period deficit, which we denote, $D_{t}$. Following the same steps as in section 4 , we see that (9.3) at $t=T$ implies

$$
E_{t} \frac{b_{t+T}}{\prod_{j=0}^{T}\left(1+r_{t+j}\right)}=(1-\gamma)^{T+1} b_{t-1}+E_{t} \sum_{s=0}^{T} \prod_{j=0}^{s-1}\left(\frac{1}{1+r_{t+j}}\right)(1-\gamma)^{T-s} D_{t+s}
$$

To ensure fiscal solvency is obtained via the fiscal authority's choice over the sequence $\{T\}_{t=0}^{\infty}$, we shall assume that the coefficient $\gamma$ is sufficiently large. In particular that will ensure that policy is Ricardian and that the PVBC is satisfied for any feasible path for the relevant variables.

\subsection{Why does fiscal policy matter in this model?}

In our discussion of consumption dynamics we indicated one way in which fiscal policy has leverage over the economy. In this section we demonstrate this point explicitly. Recall that fiscal policy matters for the level of aggregate demand in this model because it affects the discounted present value of human wealth. Define human wealth, $H_{t}$, as equal to the difference between present-value income (let $Y_{t}$ denote income in period $t$ ) and present-value lump-sum taxes (where $T_{t}$ denotes such taxes in period $t$ ). That is,

$$
H_{t}=\sum_{j=0}^{\infty}\left\{\left(\frac{1}{1+r}\right)^{j}\left(\frac{1}{1+\lambda}\right)^{j} Y_{t+j}\right\}-\sum_{j=0}^{\infty}\left\{\left(\frac{1}{1+r}\right)^{j}\left(\frac{1}{1+\lambda}\right)^{j} T_{t+j}\right\}
$$

For simplicity we assume here that the real interest rate is constant, although it will be apparent that nothing crucial hinges on this assumption. Now consider a change in the temporal profile of taxes such that the present discounted value of 
government surpluses remain unchanged. That is, consider a variation in taxes at time $t$ offset by a one-time change at $t+j$,

$$
T_{t}(1+\triangle)+\left(\frac{1}{1+r}\right)^{j}(1+\triangle) T_{t+j}=0 .
$$

That is,

$$
\triangle T_{t+j}=-(1+r)^{j} \triangle T_{t},
$$

such that

$$
B_{t-1}=\sum_{j=0}^{\infty}\left\{\left(\frac{1}{1+r}\right)^{t+j} T_{t+j}\right\}-\sum_{j=0}^{\infty}\left\{\left(\frac{1}{1+r}\right)^{t+j} G_{t+j}\right\} .
$$

In the simple representative agent model such an amendment to fiscal policy would leave all real variables unaltered since it would leave the present value of human wealth unchanged, $\triangle H=0$. Here, however, it is straightforward to show that this will not be the case. First note that the change in human wealth will be given by

$$
\triangle H_{t}=T_{t}(1+\triangle)+\left\{\left(\frac{1}{1+r}\right)^{j}\left(\frac{1}{1+\lambda}\right)^{j}\right\}(1+\triangle) T_{t+j} .
$$

It follows that for $\lambda \neq 0$

$$
\triangle H_{t}=\triangle T_{t}\left\{1-\left(\frac{1}{1+\lambda}\right)^{j}\right\} \neq 0 .
$$

Clearly, if the representative agent here faces a zero (anticipated) probability of death, then the change in present-value of human wealth is identically zero, $\triangle H_{t}=0$, and the time profile of consumption remains the same despite the temporal reallocation of taxes. So a government that cuts taxes today but leaves fiscal solvency intact can nevertheless influence the level of private sector demand. And the longer the fiscal authority waits to tighten fiscal policy to offset today's relaxation, the larger will be the impact on aggregate demand. 
However there are additional effects from fiscal policy. To see this note that in our model aggregate demand is simply given by

$$
Y_{t}^{d}=C_{t}+G_{t}
$$

The aggregate consumption function at time $t$ is given by

$$
C_{t}=\frac{1+\lambda-\beta}{1+\lambda}\left[b_{t-1}+E_{t} \sum_{s=t}^{\infty} \prod_{j=t}^{s-1}\left\{\left(\frac{1}{1+r_{t+j}}\right)\left(\frac{1}{1+\lambda}\right)^{s-t}\left(Y_{s}-T_{s}\right)\right\}\right]
$$

where we are ignoring the effect of money balances. We see that that the path of taxes impacts negatively on consumption as it reduces net wealth. Following Blanchard (1985) we construct an index of fiscal stance, IF $S_{t}$, which characterizes the net effect of fiscal variables on aggregate demand:

$$
\begin{aligned}
I F S_{t}= & G_{t}-\frac{1+\lambda-\beta}{1+\lambda}\left[E_{t} \sum_{s=t}^{\infty} \prod_{j=t}^{s-1}\left\{\left(\frac{1}{1+r_{t+j}}\right)\left(\frac{1}{1+\lambda}\right)^{s-t} G_{s}\right\}\right] \\
& +\frac{1+\lambda-\beta}{1+\lambda}\left[b_{t-1}+E_{t} \sum_{s=t}^{\infty} \prod_{j=t}^{s-1}\left\{\left(\frac{1}{1+r_{t+j}}\right)\left(\frac{1}{1+\lambda}\right)^{s-t}\left(G_{s}-T_{s}\right)\right\}\right] .
\end{aligned}
$$

The first line is the effect of government expenditure on aggregate demand when it is financed out of contemporaneous taxation, whilst the second line is the effect of financing via debt issue. To see this more clearly, recall that the government's present-value budget is

$$
b_{t-1}=-E_{t} \sum_{s=t}^{\infty} \prod_{j=t}^{s-1}\left\{\left(\frac{1}{1+r_{t+j}}\right)\left(G_{s}-T_{s}\right)\right\}
$$

where we have again partialled out the seigniorage term. Hence the index may 
now be written as,

$$
\begin{aligned}
I F S_{t}= & G_{t}-\frac{1+\lambda-\beta}{1+\lambda}\left[E_{t} \sum_{s=t}^{\infty} \prod_{j=t}^{s-1}\left\{\left(\frac{1}{1+r_{t+j}}\right)\left(\frac{1}{1+\lambda}\right)^{s-t} G_{s}\right\}\right] \\
& +\frac{1+\lambda-\beta}{1+\lambda}\left[E_{t} \sum_{s=t}^{\infty} \prod_{j=t}^{s-1}\left\{\left(\frac{1}{1+r_{t+j}}\right)\left[1-\left(\frac{1}{1+\lambda}\right)^{s-t}\right]\left(G_{s}-T_{s}\right)\right\}\right] .
\end{aligned}
$$

Here, if $\lambda=0$ we see that the second line is identically zero, and there is no net wealth effect from bonds. If, however, $b_{t-1}>0$, then outstanding bonds will tend to boost aggregate demand. The correspondence between the second line in this expression and equation (9.9) is clear.

\subsection{Why does monetary policy matter in this model?}

Monetary policy matters in this framework because of the monetary policy authority's ability to alter the short-term real interest rate. In other words a change in the level of the nominal interest rate in the presence of sticky prices means that the real interest rate must have changed, and hence that the marginal utility of consumption this period compared with next period must have altered. ${ }^{32}$

\section{Optimal Simple Rules for Fiscal and Monetary Policy}

There has been much recent interest in the performance of quantitative models, such as the one developed here, under the assumption that monetary policy follows a simple rule for the interest rate. This interest can be traced largely to the insightful analysis of US monetary policy by John Taylor (1993a). Taylor found that to a large extent US monetary policy appeared to be characterized by a systematic response of the Fed Funds rate to inflation and output deviations

\footnotetext{
${ }^{32}$ There are other effects of variations in the real rate of interest, such as via the government budget constraint, but these appear to be of second-order importance.
} 
from target or trend levels. Taylor (1999), Christiano and Gust (1999) and Chadha and Nolan (2002a) are recent evaluations of the Taylor rule in a variety of quantitative theoretical environments. We cannot review in detail the results from that literature but basically interest rate rules which entail a more than one-forone change in the nominal interest rate in response to a rise in inflation (referred to as the 'Taylor Principle') whilst responding very little to output appear to have desirable operating characteristics. ${ }^{33}$ In our set up policymakers need to decide on monetary policy and fiscal policy. Rather than simply impose a monetary rule that conforms to the Taylor principle we therefore optimize over the parameter space that spans both the monetary and fiscal policy rules, for a given functional form for both rules. In this way we shall see in what ways the addition of fiscal policy affects the optimal simple monetary rule-which in principle need not now conform to the Taylor principle. ${ }^{34}$ To be more specific, we shall assume that monetary and fiscal policy are set jointly optimal, under the assumption of perfect credibility and assuming that the policymaker has a quadratic criterion function in annualized output, inflation and interest rates. In effect, then, there is here a single policymaker which determines monetary and fiscal policy jointly, subject to a requirement that fiscal policy must at all times ensure that policy is Ricardian,

\footnotetext{
${ }^{33}$ In fact, Christiano and Gust (1999) argue that the feedback coefficient should be zero on output. As we show below, our results offer qualified support for this as far as monetary policy goes but argues strongly to the negative as far as fiscal policy is concerned. See also the discussion in Woodford (2000).

${ }^{34}$ We extend the King and Watson (1997) code to perform what is, in effect, a grid search over the policy parameters such that the policymakers loss function is minimised. Alternative code has been written by Richard Dennis (2001) to solve for optimal simple rules under rational expectations This latter algorithm, however, requires something close to what we call the $B$ matrix in (10.1) to be non-singular. For larger models that is often inconvenient since then some manual system reduction is required. Our code requires neither $A$ nor $B$ to be singular. The King and Watson (1997) reduction algorithm deals with singular $A$ matrices whilst our method of calculating the model's asymptotic variance-coviariance matrix does not require the inversion of $B$ at any step along the way. Dennis' (2001) code however can also be used to solve for the case when precommitment is not feasible.
} 
in the sense of section $2 .^{35}$

Table 1 presents some business cycle moments on monetary and fiscal policy over the postwar business cycle in the UK and US. The band-pass filtered series for output, the policy rate and the fiscal surplus as a percentage of GDP are presented in Figure 3. The policy instruments' business cycle association data is thus reasonably clear: (policy) interest rates and the fiscal surplus are procyclical, although policy rates have negative leads for output. ${ }^{36}$ The systematic and positive association of the instruments of stabilization policy, nominal rates and the fiscal surplus, with the business cycle motivate our use of simple rules for understanding monetary and fiscal policy.

\subsection{Solving the Model and Optimal Simple Rules}

In this section we describe how we solve and simulate the model and how we solve for the optimal simple rules. We use our model developed in the previous section to solve for equilibrium processes for the evolution of aggregate wealth, consumption, money holdings, inflation, the short term nominal interest rate, the level of taxation, the level of government interest-bearing debt and aggregate output. To do this we used the following equations (converted into aggregate form as required): (7.3), (7.12), (7.13), (7.16) and (7.17), (8.1) and (8.2) and (9.1), together with an equation describing the aggregate economy-wide resource constraint. The feedback coefficients in the policy rules, equations (8.1) and (8.2),

\footnotetext{
${ }^{35}$ There have been a few recent studies which have solved for optimal (simple) rules. These are Williams (1999), Erceg, Henderson and Levin (2000). These studies both focussed on Taylor-type rules. Batini, Harrison and Millard (2001) subject an open economy DSGE model to a battery of optimised rules, including Taylor rules, nominal income targteing rules, exchange rate rules and inflation targeting rules. None of the above papers have focussed on fiscal policy issues.

${ }^{36}$ The main difference between the two economies is that the volatility of the price level, inflation and, in particular, the fiscal surplus seems substantially higher in the UK compared to the US.
} 
are left unspecified and we solve for these adopting a quadratic criterion for the policymaker. In practice that means we need to calculate, for a given stochastic structure for the economy's driving processes, the asymptotic variance-covariance matrix for the economy's endogenous variables. We first linearize the model around its non-stochastic steady state. Then we make an initial guess about the optimal policy parameters (given the other parametric assumptions we have made) and verify that the model admits a unique stable rational expectations equilibrium under this parameter constellation. ${ }^{37}$ In the event that such an equilibrium exists we are able to calculate the loss function of the policymaker. We then redo this calculation for an alternative selection of policy rule parameter values, and compare losses, and continue in this way until a minimum for the loss function is located. The linearized model can be represented in the following way with all variables in percentage deviation from the steady state:

$$
A E_{t} y_{t+1}=B y_{t}+C x_{t} \quad \forall t \geq 0
$$

where $y_{t}$ is a vector of endogenous variables comprising both predetermined and non-predetermined variables including policy rules for the nominal interest rate and taxes, $x_{t}$ is a vector of exogenous variables, and $A, B$ and $C$ are matrices of fixed, time-invariant, coefficients. $E_{t}$ is the expectations operator conditional on information available at time $t$. King and Watson (1997) demonstrate that if a solution to (10.1) exists and is unique then we may write that solution in state-space form as follows,

$$
\begin{aligned}
& y_{t}=\Pi s_{t} \\
& s_{t}=M s_{t-1}+G e_{t},
\end{aligned}
$$

\footnotetext{
${ }^{37}$ We verify that our model, under the policy rules in place, meets the Blanchard-Kahn criteria by applying the state reduction algorithm described in King and Watson (1997). This is convenient since we encountered, as is generally the case in DSGE models of the sort developed in this paper, singularities in what we label the $A$ matrix. See the discussion below for more details.
} 
where the $s_{t}$ matrix includes the state variables of the model (predetermined variables along with exogenous state variables), and $e_{t}$ is a vector of shocks to the state variables. The $y_{t}$ matrix has also been augmented to include the model's exogenous state variables. Let $n p d$ denote the number of predetermined variables, $n x$ the number of exogenous state variables and let nnpd denote the number of non-predetermined variables. The dimensions of our system are as follows: $y_{t}$ is $[(n n p d+n p d+n x) \times 1], s_{t}$ is $[(n p d+n x) \times 1], \Pi$ is $[(n n p d+n p d+n x) \times(n p d+n x)]$, $M$ is $[(n p d+n x) \times(n p d+n x)]$, and $G$ is $[(n p d+n x) \times(n p d+n x)]$. We can use equations (10.2) to calculate the asymptotic variance-covariance matrix for the model's endogenous variables. (We outline this calculation in a somewhat informal manner. The interested reader should consult Hansen and Sargent, 1998). To proceed, iterate on the second set of equations. Since there are a sufficient number of stable roots, we have that

$$
s_{t}=G \sum_{j=0}^{\infty} M^{j} e_{t-j} .
$$

Using this in the first set of equations in (10.2) we get that

$$
y_{t}=\sum_{j=0}^{\infty} \Phi M^{j} e_{t-j},
$$

where $\Phi \equiv \Pi G$ is $[(n n p d+n p d+n x) \times(n p d+n x)]$. Since the stochastic shocks to the economy are assumed to be covariance stationary, it then follows that we may write,

$$
y_{t} y_{t}^{\prime} \equiv \Sigma=\sum_{j=0}^{\infty} \Phi M^{j} \Omega M^{j^{\prime}} \Phi^{\prime},
$$

where a prime denotes a transpose and $\Omega \equiv e_{t} e_{t}^{\prime}{ }^{38}$ Let $\Sigma_{x}$ denote the asymptotic variance of the annualized value of $x$. Then, using the relevant entries from the

\footnotetext{
${ }^{38}$ To derive (10.5) we have used the result that for any two conformable matrices $A$ and $B$, $(A B)^{\prime}=B^{\prime} A^{\prime}$. Note also that since our shocks are stationary, we have that $e_{t} e_{t-j}^{\prime}=0 \quad \forall j>0$.
} 
$\Sigma$ matrix for given policy rules we can evaluate the policymaker's loss function which we assume is given by

$$
L=\alpha_{1} \Sigma_{\pi}+\alpha_{2} \Sigma_{y}+\alpha_{3} \Sigma_{i}
$$

In what follows we generate sequences of systems (10.1) under alternative guesses on the optimal parameters in our policy rules which we then evaluate using (10.6). Our aim, of course, is to find parameter values which minimize (10.6), given the functional form of the rules under consideration.

\subsection{Results of simulations}

There are a number of interesting thought experiments that one could conduct in this set-up. We limit ourselves here to a small number of experiments (more are contained in Chadha and Nolan, 2002e). First we looked to see how a simple Taylor-type rule for monetary policy might be affected in the presence of a stabilizing fiscal policy. Second, how do our results change if we extend the monetary rule to incorporate feedback from expected inflation? Finally, how does one arm of policy react when the other is constrained to act in a suboptimal manner?

Recall from the literature on Taylor rules (see for example, Woodford ,1999) that it is often argued that a weight of greater than unity on inflation and a weight close to zero on contemporaneous output has desirable stabilizing properties (see also Christiano and Gust, 1999). In fact, in most studies these parameters are simply imposed and the behavior of the model analyzed under these imposed rules. Our results are given in Table 2A.

The numbers in this table correspond to the values of the optimized coefficients associated with the arguments (indicated to the left) in the reaction functions. So, 
for example, the interest rate rule reported in Table $2 \mathrm{~A}$ is given by

$$
R_{t}=1.15 \times\left(\pi_{t}-\pi^{*}\right)+0.0631 \times\left(y_{t}-y_{t}^{*}\right)+0.2511 \times R_{t-1} .
$$

In all of the simulation results reported we have constrained fiscal policy not to react to inflation. We see, then, that the Taylor principle is respected in our optimized rule, with a feedback on inflation of just over 1.5. Taylor (1993) himself argued that a value of 1.5 fits the US data. There is also, at the optimum, a weak contemporaneous feedback from output (0.06). Interest rates are autocorrelated, although to a degree that appears somewhat less than one might expect. Turning to the deficit rule, we see that the deficit reacts robustly to the output gap. The surplus:GDP ratio responds contemporaneously to the output gap with a coefficient of 0.75 (somewhat higher than Taylor's recommendation), and is more highly autocorrelated than the nominal interest rate. In Chadha and Nolan (2002e) we calibrated these simple optimized rules to the US and UK data. This exercise is intended to see if these rules - particularly for the deficit - look plausible. Figures 4 and 5 are taken from that earlier paper. Returning to Table 1 we note that the final two rows give the band-pass filtered policy instrument series for both the US and UK, where we find that the model delivers instruments with appropriate dynamics with respect to the business cycle.

We see that the rules can to some extent track actual data, although the fit is somewhat closer in the case of the UK. Towards the start of the sample, however, the optimized fiscal rules in both countries appear to imply large swings in the deficit. This reflects relatively large swings in the output gaps in both countries and the effects of the strong feedback from the output gap in our optimized rule. Our assumption that all government expenditure is on final goods and that it is financed ultimately only out of lump sum tax means that it is relatively costless for the fiscal authority to design a systematic component for fiscal policy that 
implies such wide swings in net expenditure. Nevertheless, given that our model has such a simple structure, its ability to capture some of the movement in actual data provides us with some comfort that our results provide insight.

There has been much recent interest in the welfare and stabilization properties of inflation (forecast) targeting regimes. This interest has, of course, been the result of a number of countries adopting such a nominal regime, and with a degree of success that has often appeared elusive under alternative nominal frameworks. ${ }^{39}$ Some analysts have argued that feedback from expected inflation may have desirable stabilization properties. We therefore augmented our simple Taylor rule to include the possibility of some feedback from expected inflation. The results are given in Table $2 \mathrm{~B}$.

Here we see that the inclusion of expected inflation in the monetary rule results in little change to the feedback parameter on output (in either rule). However, the feedback on contemporaneous inflation rises somewhat, and the feedback on expected inflation also appears large, however the feedback from the lagged interest rate goes almost to zero. That indicates that the smoothing of interest rates and the (credible) targeting of inflation may be substitutes in the inflation targeting framework. In practice, the impulse responses suggest that there is little difference in the behavior of this model economy under the two simple monetary-fiscal regimes outlined in Tables 2A and 2B. ${ }^{40}$ Perhaps unsurprisingly, under credible pre-commitment and coordination of monetary and fiscal policy the precise form of the monetary policy rule may not matter much.

\footnotetext{
${ }^{39}$ See Canzoneri, Nolan and Yates (1997) for a discussion of why this may be the case when credibility is an issue.

${ }^{40}$ We present impulse responses for Table $2 \mathrm{~A}$ and those for Table $2 \mathrm{~B}$, which are very similar, are available on request.
} 


\subsection{Impulse Responses}

Before assessing a number of different policy scenarios, we discuss the impulse responses, given as Figures 6,7 and 8 of output, interest rates, the fiscal balance and inflation to $1 \%$ shocks from each of the forcing variables given the optimized coefficients reported in Table 2A. From the plots of these responses, a picture emerges of monetary and fiscal policy working as a complementary sequence of choices and of little real difference between the two rules (i.e., whether inflation or expected inflation is targeted). Consequently our comments in this section apply to the behavior of our model economy under either rule.

In response to a symmetric persistent productivity shock, output responds positively and with a high degree of persistence. Inflation mirrors the response, as falling marginal costs put downward pressure on firms' prices. The optimal policy response sees the nominal interest rate fall below base, while the fiscal surplus rises. Nominal interest rates are cut in order to stabilize falling inflation and lump-sum taxation tempers aggregate demand.

Following an unanticipated monetary tightening, output remains below its steady-state level for some 10 quarters, although it is within $0.1 \%$ of base after only 3 quarters. Output falls because a monetary policy shock increases real rates. Fiscal policy responds to this monetary tightening by running a (persistent) deficit. The maximal response is in the first period. Inflation responds quickly to the monetary shock, falling by just under $0.5 \%$ in the first period and returns more than half way to base by period 2 .

A fiscal shock impacts on output via government expenditure and bonds. The increase in output and inflation caused by the impact on aggregate demand leads to a persistent but small rise in nominal interest rates. The effects of government expenditure are analyzed in Baxter and King (1993). Briefly, a rise in government expenditure on final goods results in a rise in labor supply which boosts aggregate 
output (despite pushing down on aggregate consumption). It turns out that the transmission channel of fiscal policy identified by Baxter and King (1993) is also dominant in the current set-up. In other words the wealth effect of outstanding government bonds is of second-order importance. Chadha and Nolan (2002e) demonstrate this point in more detail.

\subsubsection{Monetary-Fiscal Interactions}

We now turn briefly to two further experiments. First we assess a suggestion of Robert Mundell (1971) that monetary policy should focus on inflation control, and fiscal policy on real objectives. Table $2 \mathrm{C}$ shows that the weights in the optimal rules derived in Tables $2 \mathrm{~A}$ and $2 \mathrm{~B}$ are not particularly far from that which would be implied by the implementation of Mundell's (1971) suggestion.

Our final illustration in Table 2D shows the implications for fiscal policy from a monetary policy-maker who places a high weight on inflation stabilization. The Table shows that active monetary policy in this case engenders similarly active fiscal policy in order to reach the optimum. This means that overly aggressive monetary policy will be complemented by a similar fiscal policy in order to stabilize the economy optimally: aggression breeds aggression. In Chadha and Nolan (2002e) a number of further experiments are conducted. However the same basic intuition is present, in that when one rule is constrained to deviate from its optimized form, the other rule ends up acting to try to compensate for such sub-optimal behavior.

The four simulations in this section indicate a number of issues worth pursuing further. The Mundellian assignment strategy is near the optimum of our constrained optimal rules. Inflation targeting, or at least our version of it, does not appear to make much difference to the behavior of our model economy as the feedback from anticipated inflation substitutes for the lack of a feedback from the 
lagged interest rate. Finally, sub-optimal behavior in one rule generates a response from the other: in our final example an aggressive monetary policy optimally engendered an aggressive fiscal policy.

\section{Conclusions}

This chapter has focussed on two main issues in the study of the interaction of monetary and fiscal policy. First, because monetary and fiscal policy are linked via the public sector's present-value budget constraint, the seigniorage and real tax sequences need to be coordinated over the 'long run'. In practice a number of countries have adopted independent central banks with a primary objective being price stability. Implicitly, and sometimes explicitly, this institutional set-up implies that fiscal solvency should be a primary goal of fiscal policy. However, this has lead to a concern that monetary and fiscal policy may not be coordinated at the business cycle frequencies, with the implication that output and employment may be more volatile than necessary. We develop a model in which the optimal design of monetary and fiscal policy can be considered. 


\section{References}

[1] Aiyagari, S. R., L.J. Christiano and M. Eichenbaum, "The Output, Employment, and Interest Rate Effects of Government Consumption", Journal Of Monetary Economics (30)1 (1992) pp. 73-86.

[2] Aiyagari, S. R. and M. Gertler (1985), "The Backing of Government Bonds and Monetarism", Journal of Monetary Economics, 16(1), pp 19-44.

[3] Barro, R. J. (1974), "Are Government Bonds Net Wealth?", Journal of Political Economy, vol 82, no 6, pp 1095-1117.

[4] Barro, R. J. (1979), "On the Determination of the Public Debt", Journal of Political Economy, vol 87, no 5, part 1, pp 940-71.

[5] Barro, R. J. (1981), "Output Effects of Government Purchases", The Journal of Political Economy, Vol. 89, No. 6. December,, pp. 1086-1121.

[6] Blanchard, O. J. (1985), "Debts, Deficits and Finite Horizons" Journal of Political Economy, 93, pp.223-247.

[7] Bohn, H. (1998a), "The Behaviour of U.S. Public Debt and Deficits", Quarterly Journal of Economics, vol 113, no 3, pp 949-63.

[8] Bohn, H. (1998b), "Comment on John Cochrane, 'A frictionless view of US inflation"', NBER Macroeconomics Annual, edited by Ben S. Bernanke and Julio J. Rotemberg, MIT Press, Cambridge, Massachusetts, pp 323-84

[9] Bohn, H. (1995), "The Sustainablility of Government Deficits in a Stochastic Economy", Journal of Money Credit and Banking, 27, no.1 (February), pp257-71. 
[10] Brock, W. A. (1975), "A Simple Perfect Foresight Monetary Model" Journal of Monetary Economics, vol 1, pp 133-50.

[11] Buiter, W. H. (1998), “The Young Person's Guide to Neutrality, Price Level Indeterminacy, Interest Rate Pegs and Fiscal Theories of the Price Level", NBER Working Paper, no 6396, Cambridge, Massachusetts.

[12] Buiter, Willem (1999), "The Fallacy of the Fiscal Theory of the Price-Level", Mimeo.

[13] Calvo, G A (1983), "Staggered Prices in a Utility Maximising Framework", Journal of Monetary Economics, 12, no.3 (September), pp983-98.

[14] Calvo, G A (1985), "Macroeconomic Implications of the Government Budget Constraint: Some Basic Considerations", Journal of Monetary Economics, 15, pp95-112.

[15] Canzoneri, M. B., R. E. Cumby and B. T. Diba (2001), "Is The Price Level Determined by the Needs of Fiscal Solvency?", American Economic Review, forthcoming.

[16] Canzoneri, M. B., C. Nolan and A. Yates, (1997), 'Mechanisms for Achieving Monetary Stability: Inflation Targeting versus the ERM', Journal of Money Credit and Banking, 29(1), pp. 46-60.

[17] Cardia, E. (1991), "The Dynamics of a Small Open Economy in response to Monetary, Fiscal and Productivity Shocks", Journal of Monetary Economics, 28(3), pp.411-434.

[18] Chadha, J. S., N. Janssen and C. Nolan (2001), "Productivity and Preferences in a Small Open Economy", The Manchester School, volume 69 (1), (September), pp.57-80. 
[19] Chadha, J. S. and C. Nolan (2002a) "Inflation versus Price-Level targeting in a New Keynesian Macro-model", The Manchester School, 70 (4), pp. 570-595.

[20] Chadha, J. S. and C. Nolan (2002b) "Supply Shocks and the Natural Rate of Interest: An Exploration" in The Theory and Practice of Monetary Transmission in Diverse Economies" edited by P. J. Sinclair et al., Cambridge University Press.

[21] Chadha, J. S. and C. Nolan (2002c) "Output, Inflation and the New Keynesian Phillips Curve", DAE Working Paper No. 0204.

[22] Chadha, J. S. and C. Nolan (2002d) "The Interaction of Monetary and Fiscal Policy: When Does Aggregative Fiscal Policy Matter? In preparation.

[23] Chadha, J. S. and C. Nolan (2002e) "Operating Characteristics of Simple Rules for the Conduct of Monetary Policy and Fiscal Policy". In preparation.

[24] Chari, V. V. and P. Kehoe (1999) "Optimal Fiscal and Monetary Policy," Handbook of Macroeconomics, J. Taylor and M. Woodford, eds. (North Holland: Amsterdam).

[25] Christiano, L. J., and T. J Fitzgerald (2000), "Understanding the Fiscal Theory of the Price level", Federal Reserve Bank of Cleveland Economic Review, vol 36, no 2, pp 1-37.

[26] Cochrane, J. (1998), "A frictionless view of US inflation", NBER Macroeconomics Annual, edited by Ben S. Bernanke and Julio J. Rotemberg, MIT Press, Cambridge, Massachusetts, 323-84.

[27] Cochrane, J. (2001a), "Long term debt and optimal policy in the fiscal theory of the price level", Econometrica, Volume 69, Issue 1, January, pp69-116. 
[28] Cochrane, J. (2001b), "Money as Stock", Revised June 2001 (Original August 1999), mimeo, Chicago

[29] Dennis, R. (2001), "Solving for Simple Rules in Rational Expectations Models", Working Paper, Federal Reserve Bank of San Francisco Number 00-14.

[30] Erceg, C., D. Henderson and A. Levin, (2000), "Optimal monetary policy with staggered wage and price contracts", Journal of Monetary Economics, Vol. 46, pp 281-313.

[31] Fatas, A and I Mihov (1999), "Government Size and Automatic Stabilizers: International and International Evidence", CEPR Working Paper No., 2259.

[32] Fetter, F W (1965), Development of British Monetary Orthodoxy, 1797-1875, Cambridge: MA.

[33] Friedman, M and A. J. Schwartz (1963), A Monetary History of the United States, 1867-1960 Princeton University Press.

[34] Gayer, A, Rostow, W and Schwartz, A, (1953), The Growth and Fluctuations of the British Economy, Clarendon Press: Oxford.

[35] Hamilton, J. D., and M. A. Flavin (1986), "On the Limitations of Government Borrowing: A Framework for Empirical Testing", American Economic Review, vol 76, no 4, pp 808-19.

[36] Hansen, L P and Sargent, T J (1998), Recursive Linear Models of Dynamic Economies, Chicago: University of Chicago Press.

[37] Janssen, N, C. Nolan and R. S. Thomas (1999), "Money, Debt and Prices in the UK 1705-1996", Working Paper, Forthcoming in Economica. 
[38] Kocherlakota, N and C Phelan (1999), "Explaining the Fiscal Theory of the Price Level", Federal Reserve Bank of Minneapolis Quarterly Review, vol 23, no 4, pp14-23.

[39] Leeper, E (1991), 'Equilibria Under 'Active' and 'Passive' Monetary Policies", Journal of Monetary Economics, vol 27, no 1, pp 129-47.

[40] Leith, C and S. Wren-Lewis (2000), "Interactions Between Monetary and Fiscal Policy Rules, Economic Journal, vol 110, No. 462, March, C93-C108.

[41] Lucas, R. E., Jr (1996), "Nobel Lecture: Monetary Neutrality", Journal of Political Economy, vol. 104, no 4, pp 661-82.

[42] McCallum, B. T (1984), "Are Bond-Financed Deficits Inflationary? A Ricardian Analysis", Journal of Political Economy, vol. 91, no 1, pp 123135.

[43] McCallum, B. T (2001), "Indeterminacy, Bubbles and the Fiscal Theory of Price-Level Determination", Journal of Monetary Economics, Volume 47, No. 1, February pp 19-30.

[44] Mundell, R. A. (1971), "The Dollar and the Policy Mix: 1971", Essays in International Finance No 85, International Finance Section, Princeton University.

[45] Obstfeld, M. and K. Rogoff (183), "Speculative Hyperinflations in Maximizing Models: Can We Rule Them Out?", Journal of Monetary Economics, vol 91, no 4, pp. 675-87.

[46] O'Connell, S. A. and S. P. Zeldes (1988), "Rational Ponzi Games", International Economic Review, Vol. 29, pp. 431-450. 
[47] Rudin, W. (1976), Principles of Mathematical Analysis, Third Edition, McGraw-Hill International Edition.

[48] Sargent, T. J. (1987), Dynamic Macroeconomic Theory, Harvard University Press.

[49] Sargent, T. J. and F. R. Velde (1995), "Macroeconomic Features of the French Revolution", Journal of Political Economy, Vol. 103, no 3, pp. 474-518.

[50] Sargent, T. J. and Neil Wallace (1975), "'Rational Expectations', the Optimal Monetary Instrument, and the Optimal Money Supply Rule", Journal of Political Economy, vol. 83, no 2, pp 241-254.

[51] Sargent, T. J. and N. Wallace (1981), "Some Unpleasant Monetarist Arithmetic", Federal Reserve Bank of Minneapolis Quarterly Review, vol 5, no 3, pp 1-17.

[52] Sidrauski, M (1965), "Rational Choice and Patterns of Growth in a Monetary Economy", American Economic Review, 57, No. 2 (May), pp 534-44.

[53] Sims, C. (1994), "A Simple Model for the Study of the Price Level and the Interaction of Monetary and Fiscal Policy", Economic Theory, vol 4, no 3, pp 381-99.

[54] Sims, C. (1999), "The Precarious Fiscal Foundations of EMU", De Economist, vol 147, no 4, pp 415-36.

[55] Taylor, J. B., (1999), Monetary Policy Rules, Chicago: University of Chicago Press, NBER.

[56] Taylor, J. B., (1993), "Discretion versus Rules in Practice", CarnegieRochester Conference Series on Public Policy, vol. 39, pp195-214. 
[57] Walsh, C. (1998), Monetary Theory and Policy, Cambridge, MA: The MIT Press.

[58] Williams, J. C. (1999) "Simple Rules for Monetary Policy", Board of Governors of the Federal Reserve System, Finance and Economics Discussion Paper, No. 1999-12 February, Washington.

[59] Woodford, M. (1995), "Price Level Determinacy without Control of a Monetary Aggregate", Carnegie Rochester Conference Series on Public Policy, vol 43, pp 1-46.

[60] Woodford, M (1997), "Control of the Public Debt: A requirement for Price Stability?", in The Debt Burden and Monetary Policy, eds: G. A. Calvo, and M. A. King, MacMillan: London.

[61] Woodford, M. (1998a), Public Debt and the Price Level, Princeton University, mimeo.

[62] Woodford, M. (1998b), "Comment on John Cochrane, 'A frictionless view of US inflation"', in NBER Macroeconomics Annual, edited by B. S. Bernanke and J. J. Rotemberg, MIT Press, Cambridge, Massachusetts, pp 400-28.

[63] Woodford, M. (2000), A Neo-Wicksellian Framework for the Analysis of Monetary Policy, Princeton University, mimeo.

[64] Woodford, M. (2001), "Fiscal Requirements for Price Stability", Journal of Money, Credit and Banking, vol. 33, No. (3) August pp 669-728.

[65] Yaari, M E (1965) "Uncertain Lifetime, Life Insurance, and the Theory of the Consumer", Review of Economic Studies, 32 (April), pp.137-50. 


\section{Appendix}

\section{Exponential and Discrete Density Functions}

Here we informally show how the exponential density can be approximated by the discrete density we use in the paper. The exponential density is given by (11.1)

$$
f(\lambda)=\int_{0}^{\infty} \lambda e^{-\lambda t} d t
$$

where $\lambda$ is the constant probability of death, as in Blanchard (1985), and $\frac{1}{\lambda}$ is the expected value of remaining life. That is, the expected value of a random variable is given by

$$
E(x)=\int x f(x) d x
$$

which in the case of the exponential density just becomes

$$
E(.)=\int_{0}^{\infty} t \lambda e^{-\lambda t} d t
$$

Integrating (11.3) by parts yields

$$
\left.E(.)=-t e^{-\lambda t}\right]_{0}^{\infty}+\int_{0}^{\infty} e^{-\lambda t} d t=\frac{1}{\lambda}
$$

Now, to translate this continuous density to its discrete time analogue note that:

$$
e^{-\lambda t} \simeq\left(\frac{1}{1+\lambda}\right)^{t}
$$

The exponential density is pre-multiplied by $\lambda$, however in discrete time the above factor is not pre-multiplied by $\frac{1}{1+\lambda}$ as one might initially suppose. Note that $\lambda$ is 
the (negative) of the instantaneous growth rate of the function $e^{-\lambda t}$, so that the discrete time analogue is simply

$$
\frac{\left(\frac{1}{1+\lambda}\right)^{t}-\left(\frac{1}{1+\lambda}\right)^{t-1}}{\left(\frac{1}{1+\lambda}\right)^{t-1}}=\left(\frac{\lambda}{1+\lambda}\right)
$$

Intuitively this ensures that at each point the probability of death is constant:

$$
\sum_{t=0}^{\infty}\left(\frac{\lambda}{1+\lambda}\right)\left(\frac{1}{1+\lambda}\right)^{t}
$$

The expected value of this distribution is then derived as follows

$$
E(.)=\left(\frac{\lambda}{1+\lambda}\right) \sum_{t=0}^{\infty} t\left(\frac{1}{1+\lambda}\right)^{t}
$$

Focussing on the terms to be integrated, we see that the sum, $S$, is given by

$$
S=0+\left(\frac{1}{1+\lambda}\right)+2\left(\frac{1}{1+\lambda}\right)^{2}+3\left(\frac{1}{1+\lambda}\right)^{3}+\ldots+n\left(\frac{1}{1+\lambda}\right)^{n}
$$

Similarly,

$$
\left(\frac{1}{1+\lambda}\right) S=\left(\frac{1}{1+\lambda}\right)^{2}+2\left(\frac{1}{1+\lambda}\right)^{3}+\ldots+n\left(\frac{1}{1+\lambda}\right)^{n+1}
$$

It then follows that

$$
\begin{array}{r}
\left(\frac{\lambda}{1+\lambda}\right) S=\left(\left(\frac{1}{1+\lambda}\right)+\left(\frac{1}{1+\lambda}\right)^{2}+\left(\frac{1}{1+\lambda}\right)^{3}+\ldots+\left(\frac{1}{1+\lambda}\right)^{n}\right) \\
-n\left(\frac{1}{1+\lambda}\right)^{n+1}
\end{array}
$$

Simplifying this expression and evaluating the sum as $n \rightarrow \infty$, gives that

$$
S=\frac{\left(\frac{1}{1+\lambda}\right)}{\left(\frac{\lambda}{1+\lambda}\right)^{2}}
$$


Using this in expression (11.8) confirms that expected remaining life is constant and equal to $\lambda^{-1}$.

\section{Calculating Aggregate Consumption}

As we indicated in the text, the strong symmetry assumptions adopted mean that aggregation is generally easy. For example, whenever a given variable is constant across cohorts, we employ equation (7.18) in the main text in a straightforward way. Similarly, the aggregate evolution of wealth is the same as the representative cohort's except that $\lambda=0$. In this part of the appendix we show how we calculated equation (7.19) in the main test which is the expression governing aggregate consumption dynamics We ignore the $j$-superscripts in what follows (since all cohorts are identical). In the usual way we can calculate the expected present value of consumption. Thus, iterating on the consumption Euler equation and using the present value budget constraint we find that,

$$
\begin{aligned}
E_{t} \sum_{s=t}^{\infty} \prod_{j=t}^{s-1}\left(\frac{1}{1+i_{t+j}}\right)\left(\frac{1}{1+\lambda}\right)^{s-t} P_{s} C_{s}= \\
W_{t}+E_{t} \sum_{s=t}^{\infty} \prod_{j=t}^{s-1}\left\{\left(\frac{1}{1+i_{t+j}}\right)\left(\frac{1}{1+\lambda}\right)^{s-t}\left[P_{s} Y_{s}-T_{s}-\frac{i_{s}}{1+i_{s}} M_{s}\right]\right\} .
\end{aligned}
$$

Assuming log separability as in our characterising of the key supply-side equations, we get that the left hand-side of the above expression an be written as $\frac{1+\lambda}{1+\lambda-\beta} P_{t} C_{t}$, so that we have

$P_{t} C_{t}=\frac{1+\lambda-\beta}{1+\lambda}\left[W_{t}+E_{t} \sum_{s=t}^{\infty} \prod_{j=t}^{s-1}\left\{\left(\frac{1}{1+i_{t+j}}\right)\left(\frac{1}{1+\lambda}\right)^{s-t}\left[P_{s} Y_{s}-T_{s}-\frac{i_{s}}{1+i_{s}} M_{s}\right]\right\}\right]$

which is the solved out consumption function for a given cohort. We now want to calculate aggregate $P_{t+1} C_{t+1}-P_{t} C_{t}$. First we economize on some notation, 
rewriting (11.12) as

$$
P_{t} C_{t}=\Psi\left[W_{t}+E_{t} \sum_{s=t}^{\infty} \prod_{j=t}^{s-1}\left\{\left(\frac{1}{1+i_{t+j}}\right)\left(\frac{1}{1+\lambda}\right)^{s-t} \Theta_{s}\right\}\right]
$$

where $\Psi \equiv \frac{1+\lambda-\beta}{1+\lambda}$, and $\Theta_{s} \equiv P_{s} Y_{s}-T_{s}-\frac{i_{s}}{1+i_{s}} M_{s}$. We shall also avoid carrying around expectations operators. We construct $P_{t+1} C_{t+1}-P_{t} C_{t}$ in two steps. First we derive an expression for the evolution of aggregate 'human' wealth, $\Theta_{s}$, and then we calculate an analogous expression for aggregate financial wealth. The sum of these two expressions delivers aggregate consumption dynamics. First, then, we look to the change in aggregate 'human' wealth. Since human wealth is, by assumption, equal across cohorts (productivity is equal, the first-order conditions of money holdings are the same and there is no difference across cohorts vis a vis taxes levied) we get that,

$$
\begin{gathered}
\Psi\left[\begin{array}{c}
W_{t+1}+\Theta_{t+1}+\left(\frac{1}{1+i_{t+1}}\right)\left(\frac{1}{1+\lambda}\right) \Theta_{t+2}+ \\
-\Psi\left[W_{t}+\Theta_{t}+\left(\frac{1}{1+i_{t+1}}\right)\left(\frac{1}{1+i_{t+2}}\right)\left(\frac{1}{1+\lambda}\right)^{2} \Theta_{t+3}+. .\right.
\end{array}\right] \\
\left.\left.-\frac{1}{1+\lambda}\right) \Theta_{t+1}+\left(\frac{1}{1+i_{t}}\right)\left(\frac{1}{1+i_{t+1}}\right)\left(\frac{1}{1+\lambda}\right)^{2} \Theta_{t+2}+. .\right] .
\end{gathered}
$$

Collecting terms we see that

$$
\begin{aligned}
\Psi & \left.\begin{array}{r}
-\Theta_{t}+\left(1-\left(\frac{1}{1+i_{t}}\right)\left(\frac{1}{1+\lambda}\right)\right) \Theta_{t+1}+ \\
\left.\left(1-\left(\frac{1}{1+i_{t}}\right)\left(\frac{1}{1+\lambda}\right)\right)\left(\frac{1}{1+i_{t+1}}\right)\left(\frac{1}{1+\lambda}\right)\right)\left(\frac{1}{1+i_{t+1}}\right)\left(\frac{1}{1+\lambda}\right) \Theta_{t+2}
\end{array}\right]+ \\
& \left(1+i_{t+2}\right)\left(\frac{1}{1+\lambda}\right)^{2} \Theta_{t+3}+\ldots
\end{aligned}
$$

This expression can, with a little rearrangement, be rewritten as

$$
\Psi\left[\Theta_{t}+\frac{(1+\lambda)\left(1+i_{t}\right)-1}{(1+\lambda)\left(1+i_{t}\right)}\left[\sum_{s=t+1}^{\infty} \prod_{j=t}^{s-1}\left\{\left(\frac{1}{1+i_{t+j}}\right)\left(\frac{1}{1+\lambda}\right)^{s-(t+1)} \Theta_{s}\right\}\right]\right]
$$


We now calculate an expression for $\Psi\left[W_{t+1}-W_{t}\right]$. First we recall that we now need to work with aggregate financial wealth. That is

$$
W_{t}=M_{t-1}+B_{t-1}
$$

Using this in the flow budget constraint we find after some manipulation that

$$
W_{t}+P_{t} C_{t}+\frac{W_{t+1}}{1+i_{t}}-\Theta_{t}
$$

Therefore the change in wealth may be written as,

$$
\Psi\left[\frac{i_{t}}{1+i_{t}} W_{t+1}+\Theta_{t}-P_{t} C_{t}\right]
$$

and combining this with expression (11.14) we get that

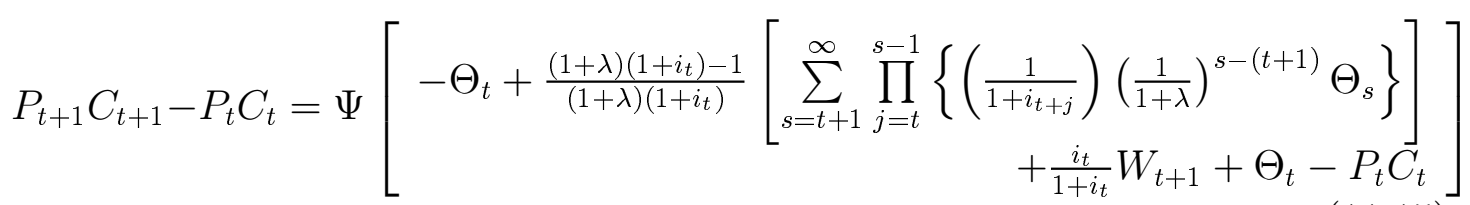

However, we already know that

$$
P_{t+1} C_{t+1}=\Psi\left[W_{t+1}+\sum_{s=t+1}^{\infty} \prod_{j=t}^{s-1}\left\{\left(\frac{1}{1+i_{t+j}}\right)\left(\frac{1}{1+\lambda}\right)^{s-(t+1)} \Theta_{s}\right\}\right]
$$

so we can re-write (11.15) as

$$
\begin{aligned}
P_{t+1} C_{t+1}-P_{t} C_{t}=\Psi\left[-\Theta_{t}+\frac{(1+\lambda)\left(1+i_{t}\right)-1}{(1+\lambda)\left(1+i_{t}\right)}\left[\frac{P_{t+1} C_{t+1}}{\Psi}-W_{t+1}\right]\right] \\
+\Psi\left[\frac{i_{t}}{1+i_{t}} W_{t+1}+\Theta_{t}-P_{t} C_{t}\right]
\end{aligned}
$$

And straightforward simplification results in:

$$
E_{t} P_{t+1} C_{t+1}=\left(1+i_{t}\right) \beta P_{t} C_{t}-\lambda \phi E_{t} W_{t+1}
$$

which is (7.19) in the main text. 


\section{Parameterization of Model}

The table outlines the baseline parameter values that we adopt for the calibration of the model. More discussion of these and the driving processes that we adopt can be found in Chadha and Nolan (2002e). The post-World War II UK and US dataset is standard. The US dataset runs from 1955:1 to 2000:4: we use the Federal Funds rate as the policy instrument in the Taylor Rule; annual inflation is measured as the four quarter percentage change in the All-Items CPI; GDP in 1995 constant prices is detrended by a quadratic time trend and the Federal Government surplus or deficit is given as as a proportion of GDP. For the UK: we use the base rate as the policy instrument; annual inflation is measured as the four quarter percentage change in the RPI; GDP in 1995 constant prices is detrended by a quadratic time trend and the Public Sector Cash Requirement is given as a proportion of GDP, after being seasonally adjusted by X12.

\begin{tabular}{lll}
\multicolumn{3}{l}{ Calibration parameters for quarterly model } \\
\hline \hline Symbol & Value & Description \\
\hline$\lambda$ & 0.00357 & Expected life remaining: 70 years \\
$r$ & 0.0125 & Real interest rate \\
$\beta$ & 0.95 & Subjective discount factor \\
$\delta$ & 0.053 & Subjective discount rate \\
$\gamma$ & 0.06 & Rate of debt retirement \\
$\frac{c}{y}$ & 0.6 & Steady-state consumption-output ratio \\
$\frac{m}{w}$ & 0.1 & Steady-state money-wealth ratio \\
$\kappa$ & 0.5 & Phillips curve slope \\
$\frac{w}{c}$ & 0.7 & Steady-state wealth-consumption ratio \\
\hline \hline
\end{tabular}

The model is calibrated at a quarterly frequency using more or less standard parameter values. We assume that $\lambda$ is determined as a result of the representative agent expecting to live to 70 . The discount factor, $\beta$, is set at 0.95. Numerical investigations led us to set the debt retirement rate, $\gamma$, to 0.06. The consumption:income ratio, $c / y$, is equal to 0.6 , while the steady state 
money:wealth ratio, $m / w$, was chosen to be 0.1 . Roughly speaking the average size of the UK debt-to-GDP ratio over the post-war period has been some $40 \%$. Together with our assumption for $c / y$, implies that the steady-state wealth:income ratio for this simple model economy is 0.7 .

Let $a_{t}, f_{t}$, and $h_{t}$ denote the log detrended processes for productivity, fiscal and monetary innovations, respectively. We then assume they can be described adequately for our purposes as follows,

$$
\left[\begin{array}{c}
a_{t} \\
f_{t} \\
h_{t}
\end{array}\right]=\left[\begin{array}{ccc}
\rho_{a} & 0 & 0 \\
0 & \rho_{f} & 0 \\
0 & 0 & \rho_{q}
\end{array}\right]\left[\begin{array}{c}
a_{t-1} \\
f_{t-1} \\
h_{t-1}
\end{array}\right]+\left[\begin{array}{c}
x_{t} \\
g_{t} \\
q_{t}
\end{array}\right],
$$

where $x_{t}, g_{t}$, and $q_{t}$ are the shocks respectively to productivity, fiscal and monetary innovations. We adopted an agnostic strategy for setting the covariation structure of the forcing variables. First we estimated Solow residuals, Taylor Rules and Fiscal rule equations on US and UK data and found little difference in the standard errors of the respective equations. Similarly Cardia (1991) found that the standard deviation of shocks to the monetary and fiscal processes were of similar magnitude in the US data, whilst in the German data the standard deviations of fiscal and productivity shocks were of a similar size. In practice, then, we decided simply to set $\sigma_{a}=\sigma_{f}=\sigma_{q}=0.01$. In terms of the persistence parameters we chose the following: $\rho_{a}=0.9, \rho_{f}=0.9$, and $\rho_{q}=0$. In Chadha and Nolan (2002e) we discuss these stochastic settings further. We found that our results were fairly insensitive to alternative plausible assumptions vis a vis persistence and volatility of underlying shocks. 
Financial Surplus:GNP and Price Level (inverse scale rhs)

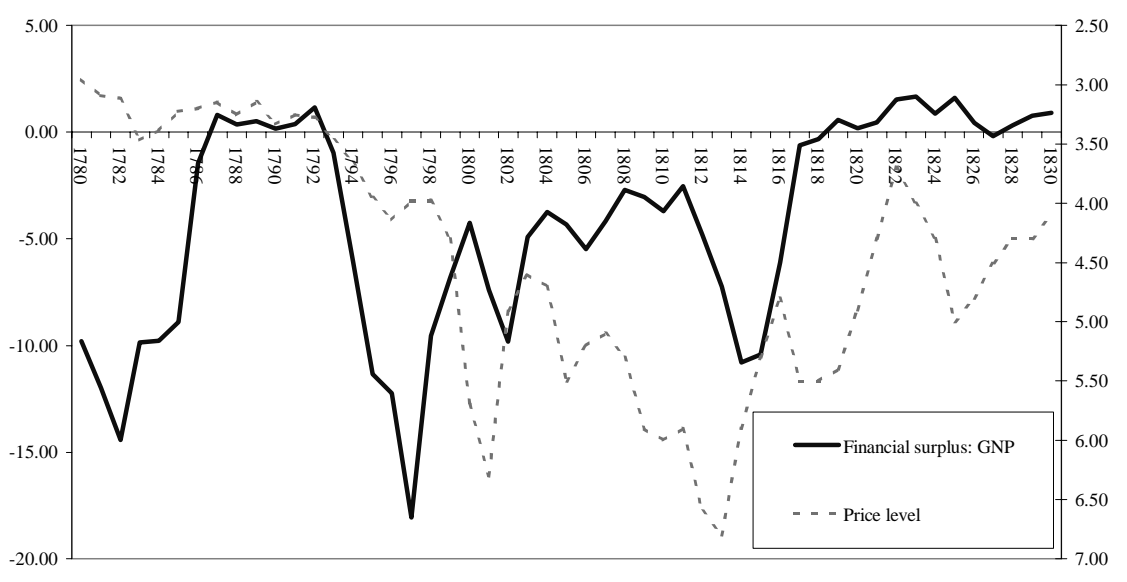

Figure 1: Price and Fiscal Surpluses

Money Supply and Price Level (rhs) (1780-1830)

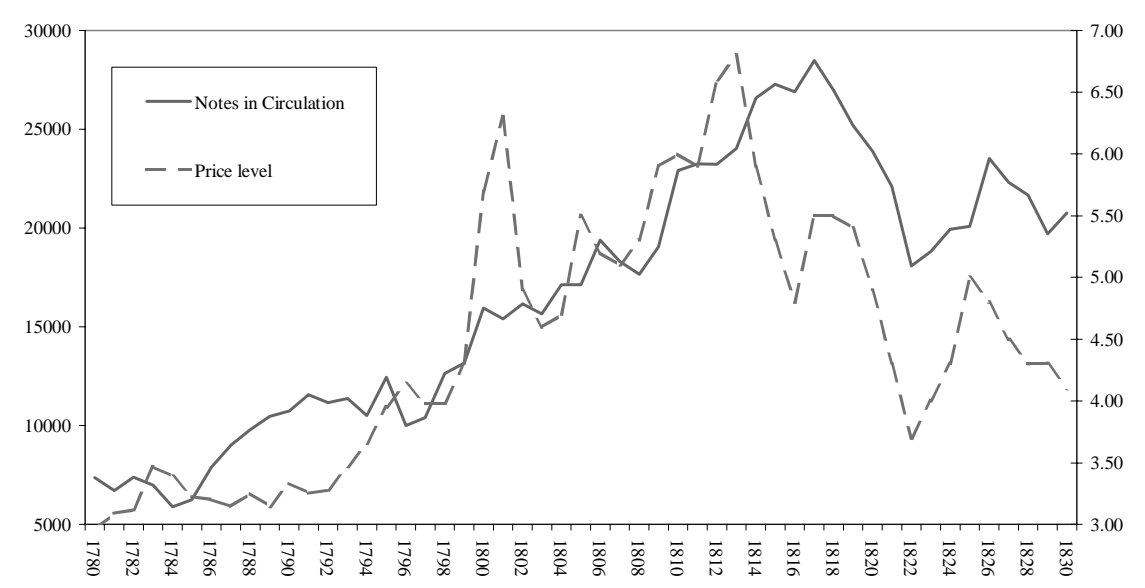

Figure 2: Money and Prices 


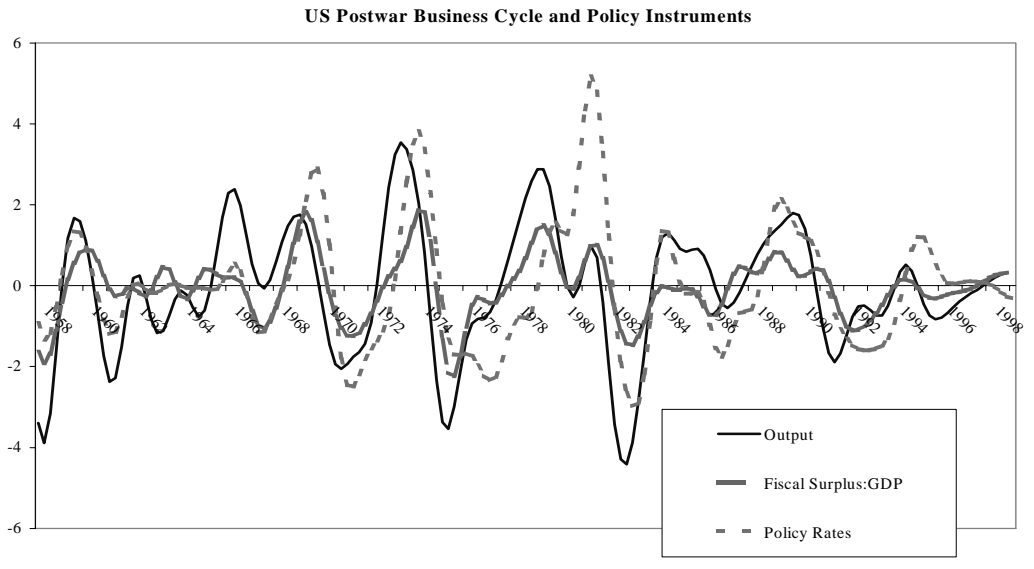

UK Postwar Business Cycle and Policy Instruments

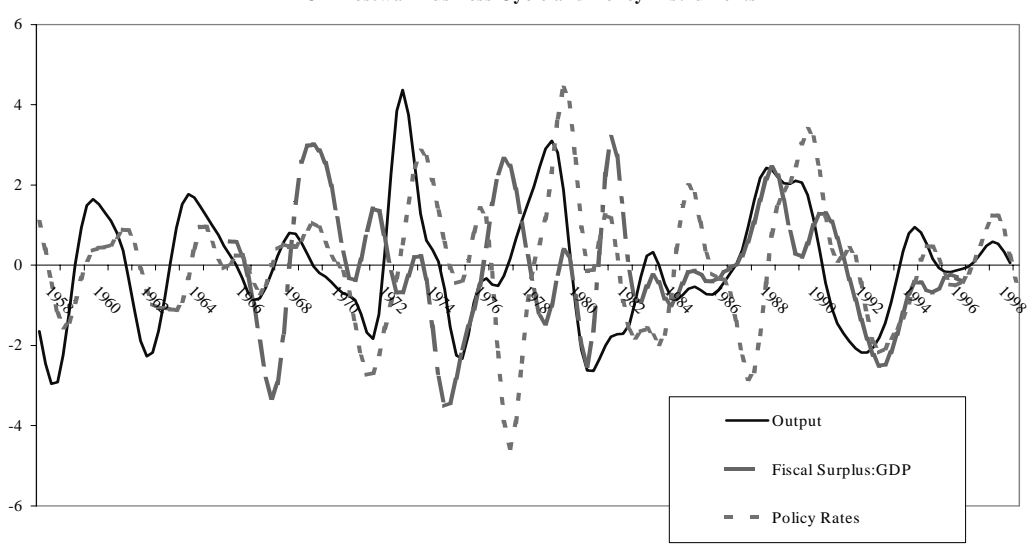

Figure 3: Business Cycle in US and UK 
Optimal Taylor Rule and Federal Funds Rate: US 1990-2000

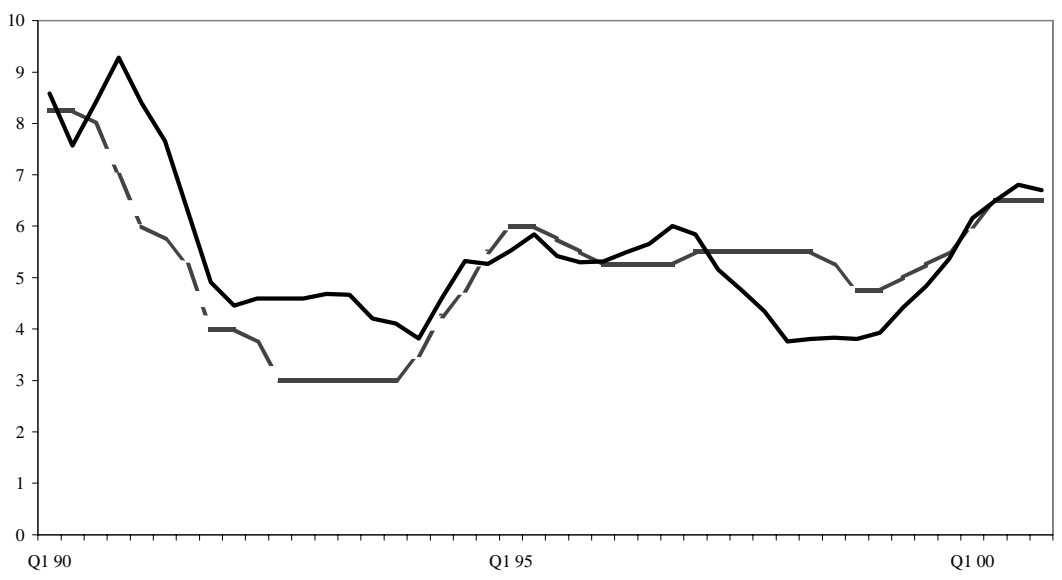

Optimal Fiscal Rule and Fiscal Surplus: US 1990-2000

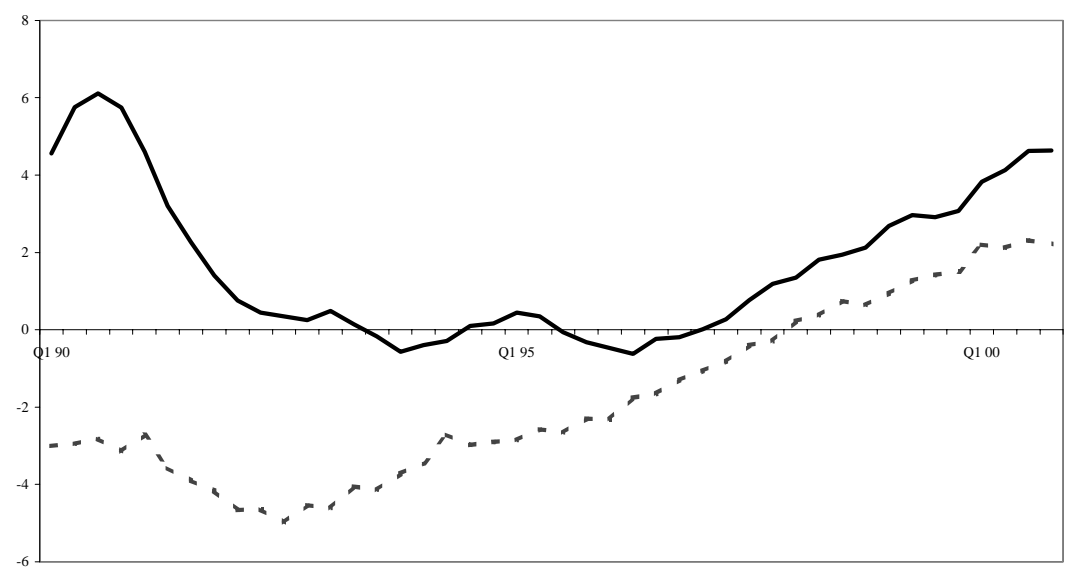

Figure 4: US Policy - Actual (dotted) and Optimal (dotted). 


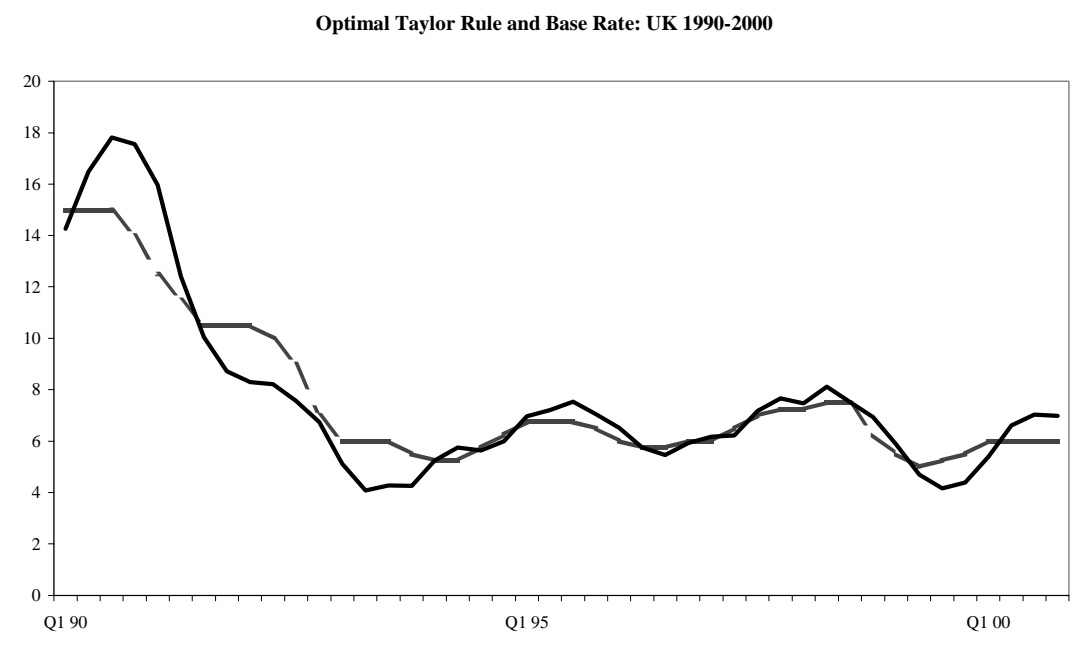

Optimal Fiscal Rule and Budget Surplus: UK 1990-2000

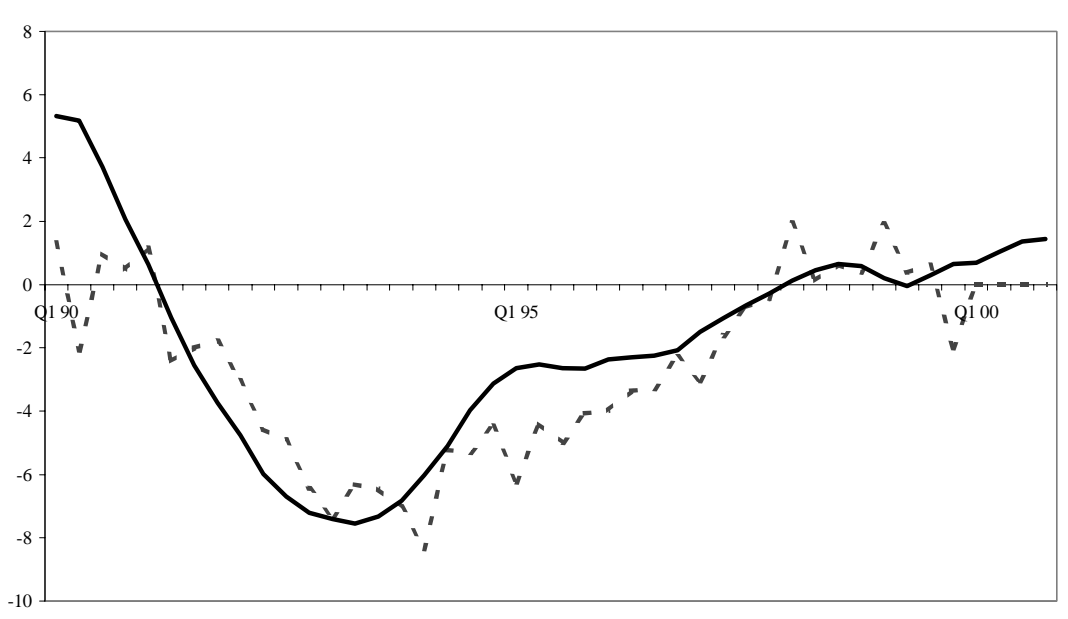

Figure 5: UK Policy - Actual (dotted) and Optimal (dotted). 
output in response to productivity shock

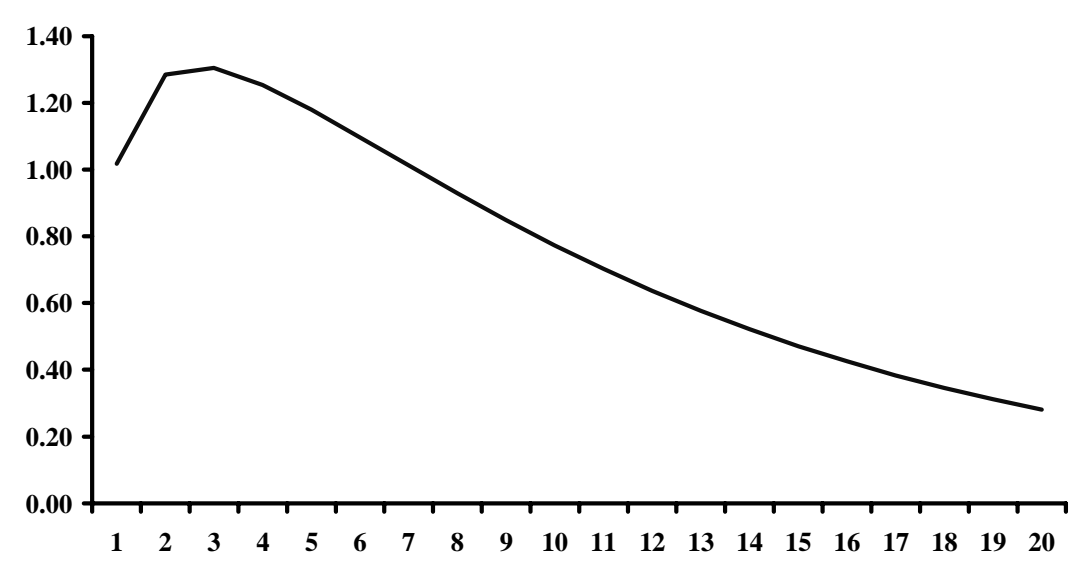

nominal interest in response to productivity shock

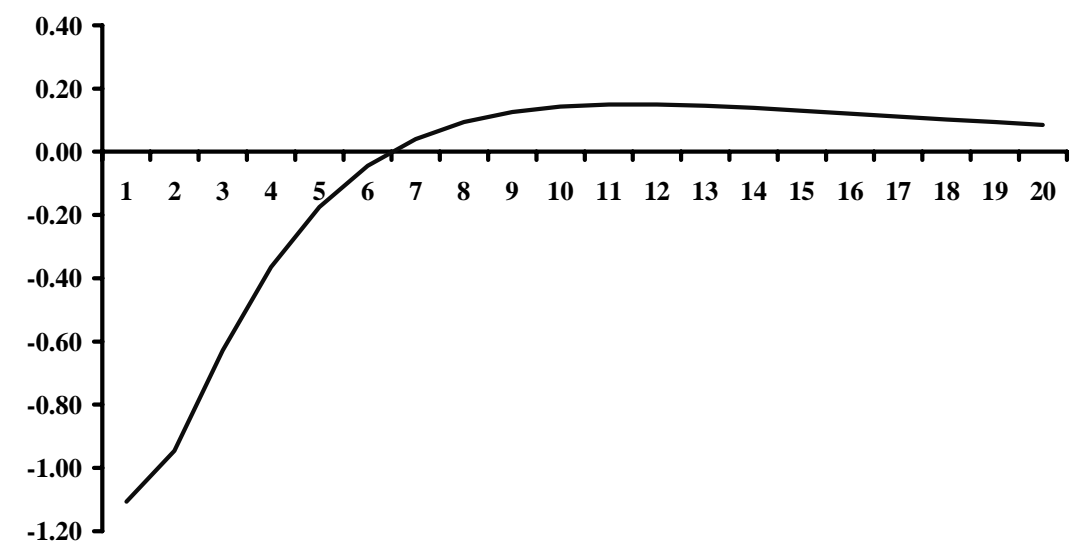


Surplus in response to productivity shock

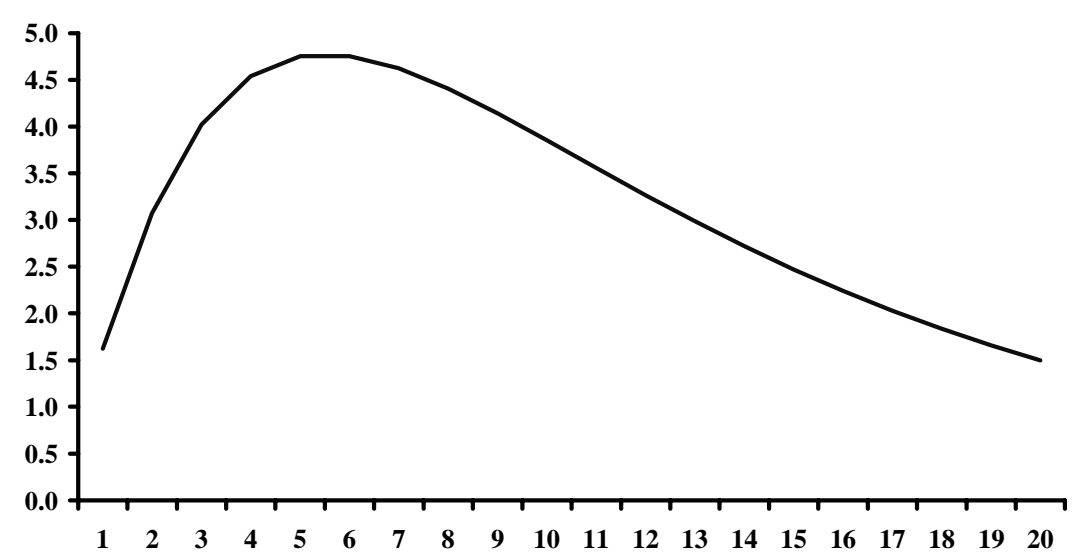

Inflation in response to productivity shock

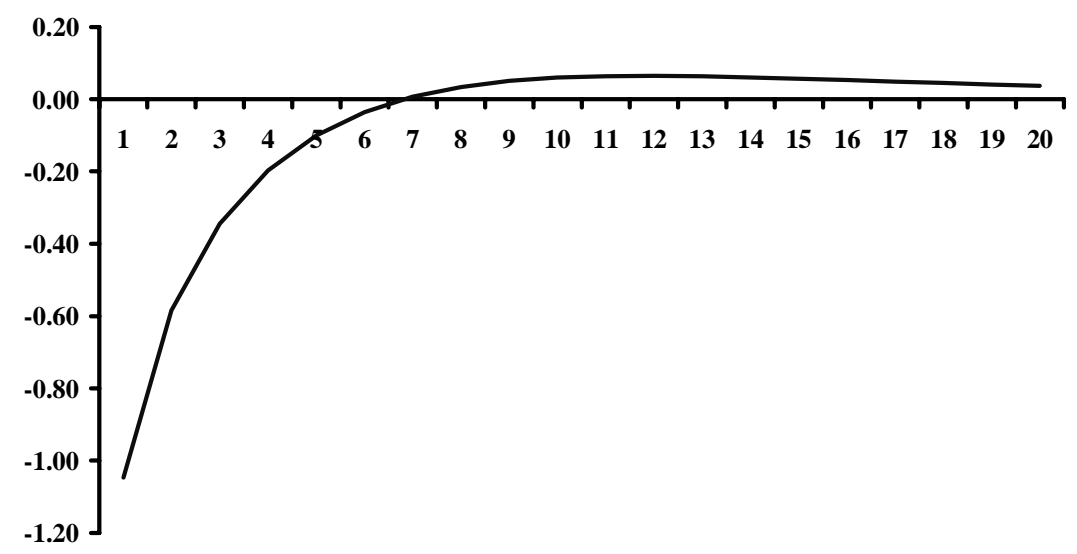

Figure 6: Key responses to a productivity shock 
output in response to monetary shock

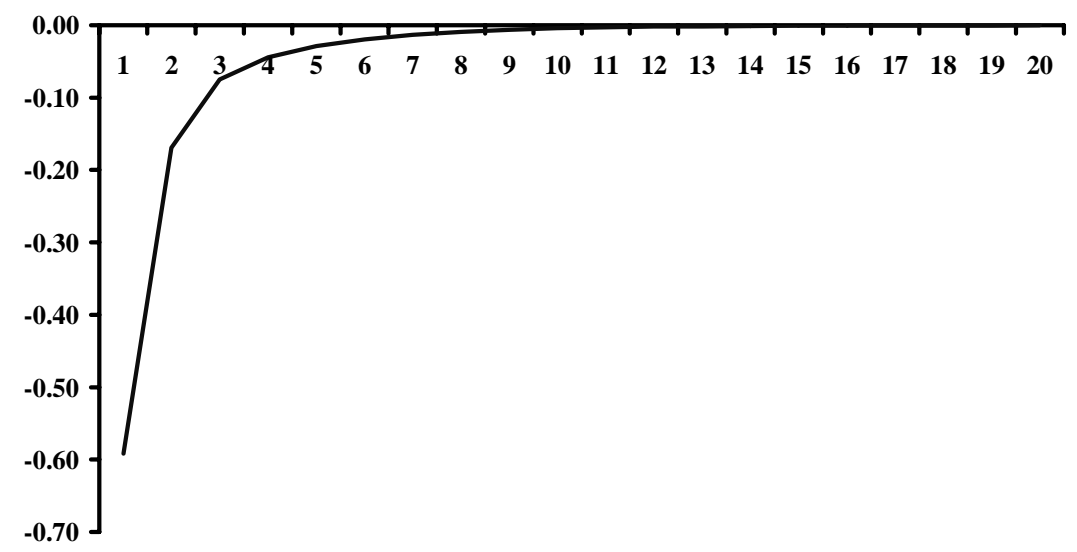

nominal interest in response to monetary shock

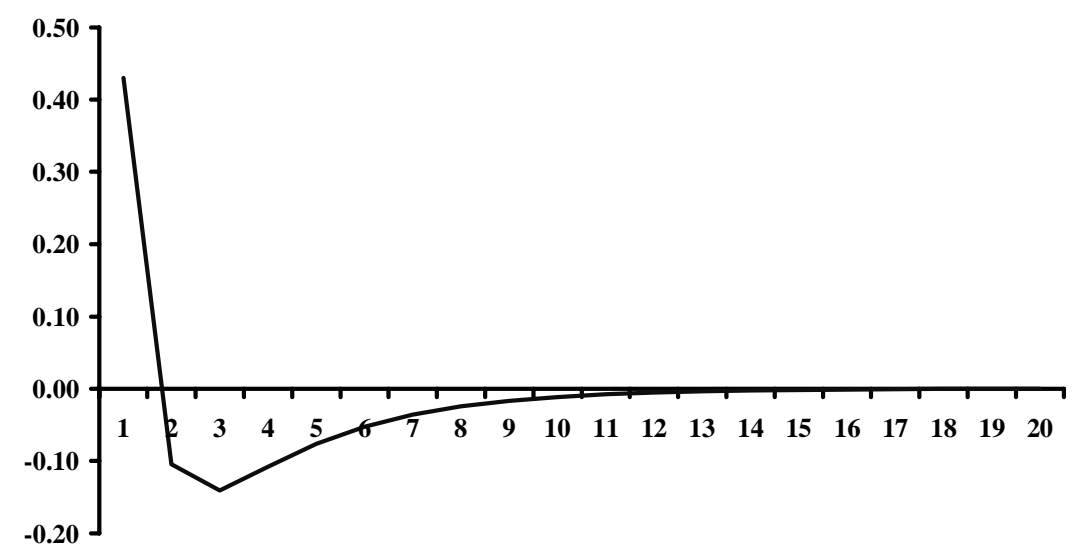


Surplus in response to monetary shock

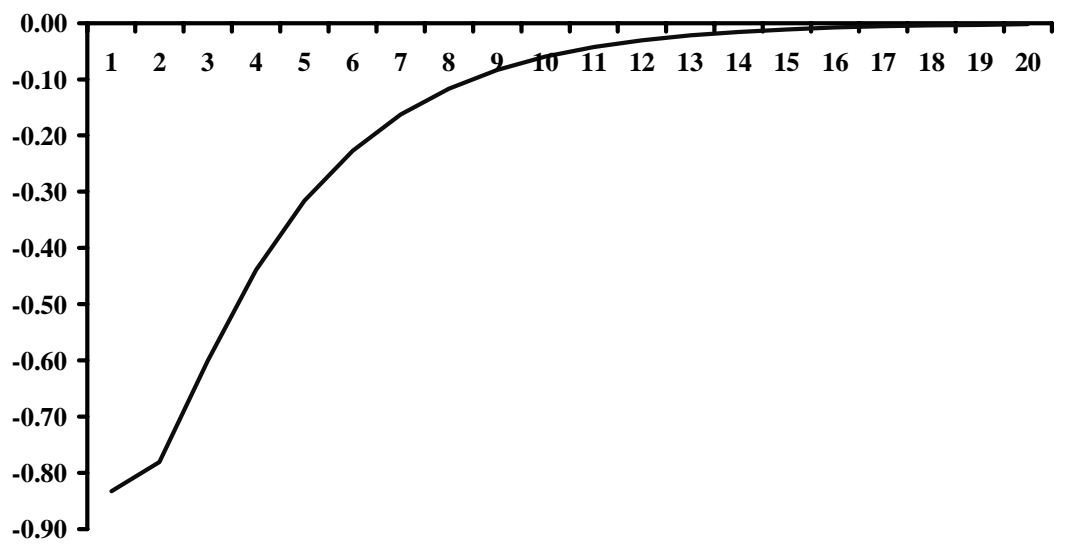

Inflation in response to monetary shock

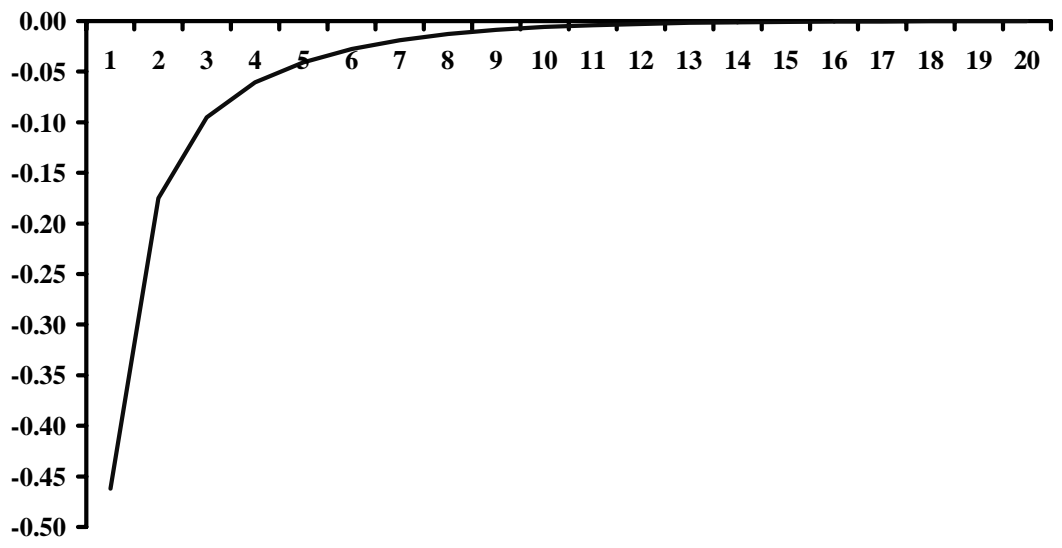

Figure 7: Key responses to a monetary shock 
output in response to fiscal shock

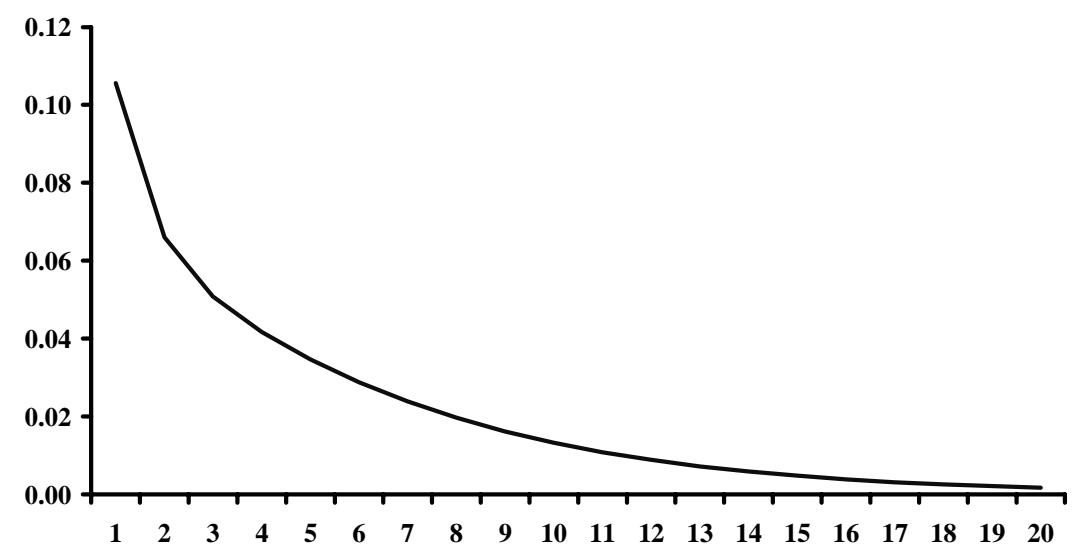

nominal interest in response to fiscal shock

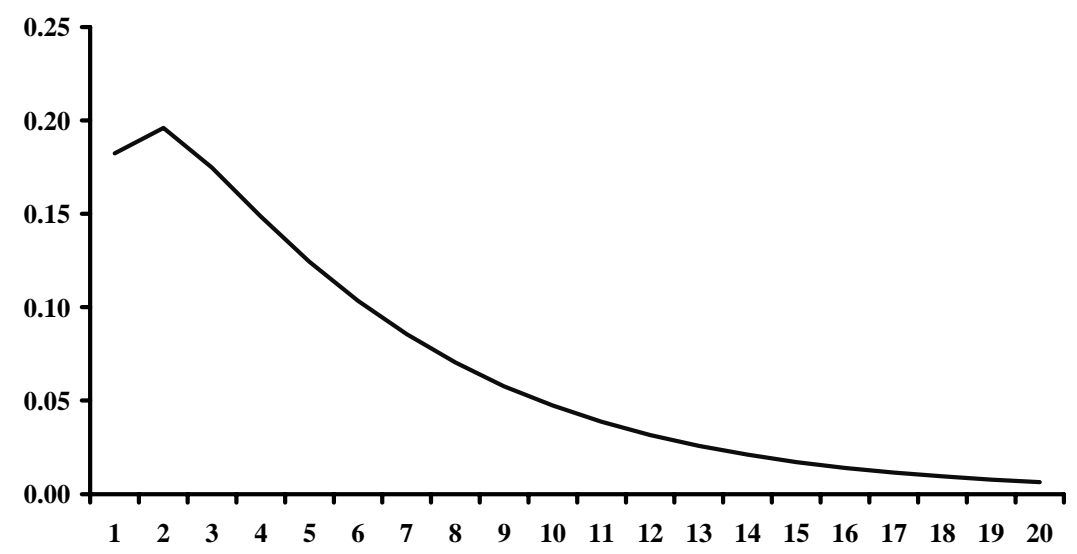


Surplus in response to fiscal shock

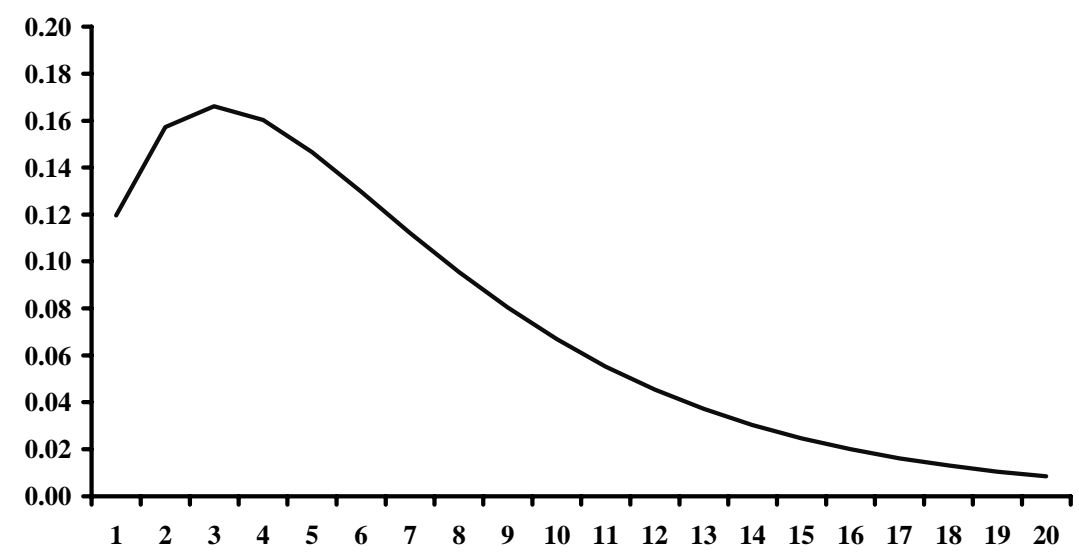

Inflation in response to fiscal shock

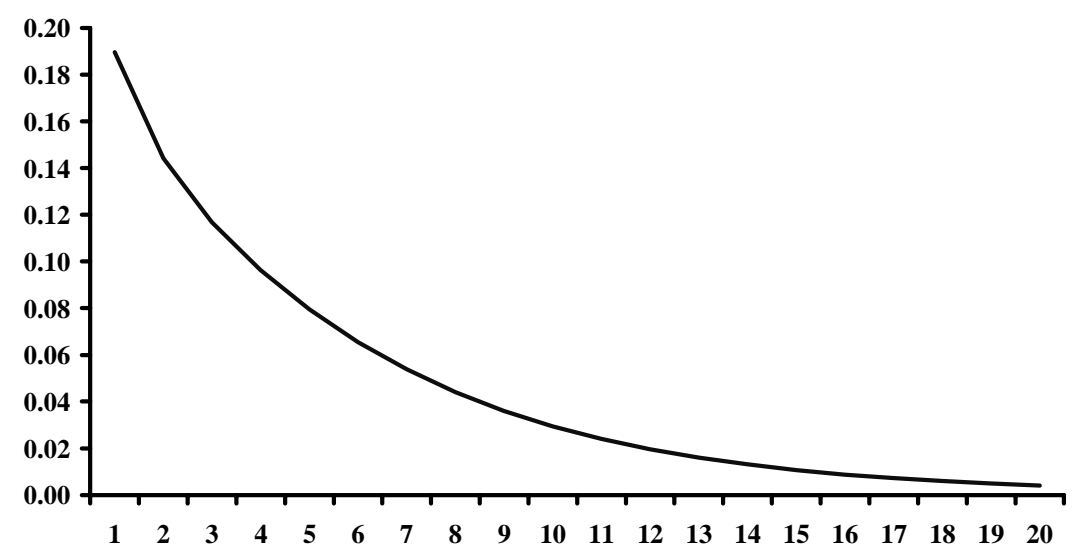

Figure 8: Key responses to a fiscal shock 
Table 1a: US Business Cycle Dynamics

\begin{tabular}{cccccccccccc}
\hline \hline & $\sigma_{i}$ & $\frac{\sigma_{i}}{\sigma_{y}}$ & $y_{t-4}$ & $y_{t-3}$ & $y_{t-2}$ & $y_{t-1}$ & $y_{t}$ & $y_{t+1}$ & $y_{t+2}$ & $y_{t+3}$ & $y_{t+4}$ \\
\hline \hline$y_{t}$ & 1.563 & 1.0 & 0.140 & 0.415 & 0.696 & 0.912 & - & - & - & - & - \\
$i_{t}$ & 1.500 & 0.960 & 0.435 & 0.554 & 0.631 & 0.627 & 0.513 & 0.308 & 0.039 & -0.235 & -0.464 \\
$s_{t}$ & 0.772 & 0.494 & 0.367 & 0.563 & 0.713 & 0.776 & 0.724 & 0.541 & 0.285 & 0.018 & -0.205 \\
\hline$\hat{i}_{t}$ & 2.141 & 1.370 & 0.669 & 0.610 & 0.436 & 0.306 & 0.100 & -0.116 & -0.293 & -0.420 & -0.493 \\
$\hat{s}_{t}$ & 3.794 & 2.427 & 0.625 & 0.828 & 0.946 & 0.946 & 0.824 & 0.603 & 0.344 & 0.094 & -0.109 \\
\hline \hline
\end{tabular}

Table 1b: UK Business Cycle Dynamics

\begin{tabular}{cccccccccccc}
\hline \hline & $\sigma_{i}$ & $\frac{\sigma_{i}}{\sigma_{y}}$ & $y_{t-4}$ & $y_{t-3}$ & $y_{t-2}$ & $y_{t-1}$ & $y_{t}$ & $y_{t+1}$ & $y_{t+2}$ & $y_{t+3}$ & $y_{t+4}$ \\
\hline \hline$y_{t}$ & 1.458 & 1.0 & 0.255 & 0.508 & 0.751 & 0.932 & - & - & - & - & - \\
$i_{t}$ & 1.496 & 1.026 & 0.605 & 0.624 & 0.591 & 0.487 & 0.310 & 0.085 & -0.155 & -0.372 & -0.536 \\
$s_{t}$ & 1.503 & 1.031 & 0.033 & 0.122 & 0.181 & 0.204 & 0.201 & 0.190 & 0.187 & 0.195 & 0.207 \\
\hline$\hat{i}_{t}$ & 3.973 & 2.275 & 0.424 & 0.314 & 0.156 & -0.039 & -0.240 & -0.413 & -0.526 & -0.566 & -0.536 \\
$\hat{s}_{t}$ & 5.423 & 3.719 & 0.466 & 0.550 & 0.608 & 0.626 & 0.599 & 0.522 & 0.419 & 0.306 & 0.199 \\
\hline \hline
\end{tabular}

Notes: (i) all data are from 1955:1 to 2001:4; (ii) we show the results for Band-Pass filtered series with a 12-quarter moving average window; (iii) HodrickPrescott filtered series are available on request; (iv) column 2 is the standard deviation of the filtered series, $i$; $(\mathrm{v})$ column 3 is the standard deviation scaled by output; (vi) we examine the correlation with output at leads and lags; (vii) the first row gives the autocorrelation function of outpu; (viii) the final two rows are the simulated policy instruments of interest rates and the fiscal surplus.. 
Table 2A: The Simple Taylor Rule

\begin{tabular}{cccc}
\hline \hline & Interest rate rule & & Fiscal Rule \\
\cline { 2 - 4 }$\pi_{t}-\pi^{*}$ & 1.1513 & $\pi_{t}-\pi^{*}$ & 0 \\
$y_{t}-y_{t}^{*}$ & 0.0631 & $y_{t}-y_{t}^{*}$ & 1.7522 \\
$R_{t-1}$ & 0.2511 & $D_{t-1}$ & 0.5712 \\
\hline
\end{tabular}

Table 2B: Inflation Expectations Augmented Taylor Rule

\begin{tabular}{cccc}
\hline \hline & Interest rate rule & & Fiscal Rule \\
\cline { 2 - 4 }$\pi_{t}-\pi^{*}$ & 1.0981 & $\pi_{t}-\pi^{*}$ & 0 \\
$E_{t} \pi_{t+1}-\pi^{*}$ & 0.2927 & $E_{t} \pi_{t+1}-\pi^{*}$ & 0 \\
$y_{t}-y_{t}^{*}$ & 0.0548 & $y_{t}-y_{t}^{*}$ & 1.8151 \\
$R_{t-1}$ & 0.0958 & $D_{t-1}$ & 0.5271 \\
\hline
\end{tabular}

Table 2C: Mundell Assignment Rule

\begin{tabular}{cccc}
\hline \hline & Interest rate rule & & Fiscal Rule \\
\cline { 2 - 4 }$\pi_{t}-\pi^{*}$ & 1.07 & $\pi_{t}-\pi^{*}$ & - \\
$y_{t}-y_{t}^{*}$ & - & $y_{t}-y_{t}^{*}$ & 1.11 \\
$R_{t-1}$ & 0.19 & $D_{t-1}$ & 0.65 \\
\hline
\end{tabular}

Table 2D: Fiscal Policy Implications of the High Inflation Aversion

\begin{tabular}{cccccccc}
\hline \hline & IRR & FR & IRR & FR & IRR & FR & \\
\cline { 2 - 8 }$\pi_{t}$ & 4.5 & - & 3.5 & - & 2.0 & - & $\pi_{t}$ \\
$y_{t}$ & 0.1 & 3.06 & 0.1 & 3.03 & 0.1 & 2.57 & $y_{t}$ \\
$R_{t-1}$ & 0.2 & 0.44 & 0.2 & 0.47 & 0.2 & 0.52 & $D_{t-1}$
\end{tabular}

Note: The columns headed IRR refer to Interest Rate Rule and those headed FDR refer to the Fiscal Deficit Rule. For IRR go to the lhs column for a key and for FDR go to the rhs for a key. 